\title{
Chitosan based antibacterial composite materials for leather industry: a review
}

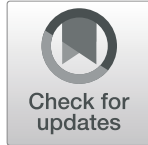

\author{
Linlin Yuan', Qingda Yao ${ }^{2,3}$, Yongxian Liang ${ }^{2,3}$, Ye Dan ${ }^{4}$, Yixiao Wang ${ }^{5}$, Huitao Wen ${ }^{1,2}$, Yiqing Yang ${ }^{2,3}$ and \\ Weihua Dan ${ }^{1,2^{*}}$
}

\begin{abstract}
Chitosan is an amorphous translucent substance with a structural unit similar to the polysaccharide structure of the extracellular matrix, It has good antibacterial, biocompatible, and degradable properties. It has important application value in leather, water treatment, medicine, food and other fields, so chitosan and its modified products have received widespread attention. This article reviewed the preparation methods of chitosan-based antibacterial composites in recent years, including chitosan/collagen, chitosan/graphene, chitosan/tannic acid, and chitosan/ polyethylene glycol composite materials, elaborates their modification methods and antibacterial mechanism were reviewed in detail, and its applications in the leather industry as antibacterial auxiliaries and water treatment antibacterial adsorption materials were discussed. Finally, the future development and challenges of chitosan-based composite materials in the leather industry were forecasted.
\end{abstract}

Keywords: Chitosan, Antibacterial, Leather, Composites, Application

\section{Introduction}

Chitin is the most abundant and renewable polysaccharides in the marine environment, and it also ranks as the second abundant resource on earth after cellulose. As it is known to us, chitin is the main structural polymer in the fungal cell wall. It is also present on exoskeletons of arthropods and insects [1-3]. The regular ring structure inside the chitin molecule has strong hydrogen bonding, which makes it have high crystallinity and poor solubility. Chitin is not soluble in polar solvents such as water, thus making its application is very limited [4]. Chitin is $\beta$-(1,4)-2-acetamido-2-deoxy-D-glucopyranose, which is connected to disaccharide repeat units through $\beta-(1,4)$ D-glycosidic bonds to form linear high polymer, its chemical structure is similar to cellulose [5]. The active functional group at the $\mathrm{C} 2$ position of cellulose is

\footnotetext{
* Correspondence: danweihua_scu@126.com

${ }^{1}$ National Engineering Research Center of Clean Technology in Leather

Industry, Sichuan University, Chengdu, Sichuan, P. R. China

${ }^{2}$ Fujian Key Laboratory of Green Design and Manufacture of Leather, Jinjiang,

Fujian, P. R. China

Full list of author information is available at the end of the article
}

hydroxyl, chitin is $\mathrm{N}$-acetylamino, and chitosan is amino and $\mathrm{N}$-acetylamino. Chitosan (CS) is a high molecular linear polysaccharide obtained by partially or completely deacetylating chitin. Chitosan with different degrees of deacetylation has different intensity of positive charge. The solubility and activity of chitosan are related to the degree of deacetylation. Generally, the higher the degree of deacetylation, the easier it is to functionally modify its chemical modification. Up to now, chitosan is the only cationic animal fiber and basic polysaccharide [6]. According to the different amount of positive charge and the molecular weight of chitosan, chitosan shows different biocompatibility and biological activity [7].

The C-3 primary hydroxyl group and C-6 secondary hydroxyl group of chitosan have extremely high activity, which can be modified to produce functional materials with excellent water solubility, antibacterial performance, biological activity, and physical and mechanical strength, thereby expanding the application range of chitosan [8]. This has become a research hotspot in the fields of textile [9], electroplating [10], medical treatment [11], water treatment [12], etc. The antibacterial activity 
of chitosan is affected by many internal factors and external factors, such as the type of chitosan and microorganisms, the degree of chitosan polymerization, the degree of deacetylation of chitosan, and the $\mathrm{pH}$ value of the solvent, etc. [13-16]. By modifying chitosan, researchers have developed chitosan derivatives with higher antibacterial activity, such as chitosan/collagen [10], chitosan/graphene [17], chitosan/tannin acid [18], chitosan/polyethylene glycol [19], etc.

The leather industry is one of the pillar industry of Chinese light industry, and the output of leather products ranks the first in the world, with a more than 50\% international market share [19]. The core of the sustainable development of the leather industry lies in green leather and functional leather. Chitosan's excellent adsorption, antibacterial activity, biocompatibility, and degradability properties, as well as derivatives derived from functional modification of the active functional groups of chitosan may be the key to promote the development of the leather industry [20]. Chitosan and its derivatives are rich in materials, widely sourced, easy to prepare, and have excellent properties such as antibacterial properties. At present, there are many shortcomings in the leather industry, such as leather products are susceptible to microbial erosion, the amount of antimicrobial chemicals is huge with strict control, sewage contains many microorganisms and the pollution treatment is difficult. If the large-scale application of chitosan-based composite materials in the leather industry and the introduction of chitosan-based tanning agents, additives, water treatment adsorbents and other materials, these problems will likely be resolved. With the ever-decreasing fossil resources, it has been a hot spot for many researchers to know how to make full use of the chitosan and its derivatives to promote the green and functional development of the leather industry.

Starting from the chitosan-based composites, this paper focused on the preparation and mechanism of chitosan/collagen, chitosan/graphene, chitosan/tannin acid, chitosan/polyethylene glycol, and then briefly analyzed the modification methods to improve the properties of composite materials. Finally, the application of chitosanbased composite materials in the leather industry was discussed and prospected.

\section{Chitosan-based composite material}

\subsection{Chitosan/collagen composite material}

Collagen is the main protein that constitutes animal skin. Among dermal proteins, collagen accounts for 80 $85 \%$. The basis of the leather industry is collagen chemistry, and collagen is susceptible to microbial attack. If chitosan and collagen can be effectively compounded thus giving antibacterial properties to the chitosan / collagen composite material, it can promote the rapid development of the leather industry. Therefore, the premise of promoting the application of chitosan-based composite materials in the leather industry is to study the interaction of collagen with chitosan and chitosan derivatives. It is well known that collagen molecules have the triple helix characteristics which gives it low antigenicity, high biocompatibility, and the ability to support cell growth [3]. However, collagen molecules are sensitive to heat, and they would easily transform into random spiral gelatin when the temperature is close to the thermal denaturation temperature (Td). Moreover, even at temperatures well below $\mathrm{Td}$, they are easily contaminated by bacteria in the air, such as Staphylococcus aureus and E. coli, making it difficult to preserve and maintain activity at normal indoor temperature [10]. Taravel et al. [21, 22] and Domard et al. [23] found that collagen and chitosan were soluble in various solvents on a molecular scale at room temperature. At present, the preparation methods of chitosan/collagen composite materials mainly include solution blending method [24], electrophoretic deposition method [25], freeze-drying method [8] and the like. The interaction between chitosan and collagen promotes the formation of complexes through electrostatic interactions or hydrogen bonding. Chitosan has cationic properties, It can interact with the anionic part of amphiphilic collagen molecules [26]. Wei et al. [10] found that chitosan and collagen had a synergistic effect of coupling so that the elastic modulus Ec of the composite exceeds the upper limit predicted by Voigt's law for two-phase composites. In addition to forming a matrix around collagen fibers, chitosan also plays a key role in the adhesion between collagen fibers, helping to form a more stable collagen fiber network [24].

However, the mechanical stability and durability of chitosan/collagen composites are relatively low, and the rapid degradation rate under the action of enzymes and heat has limited their deep application as biomaterials. Cross-linking is one of the most effective methods to further the properties of chitosan/collagen composites [24]. Chitosan/collagen can be physically cross-linked by heat treatment. Oliveira et al. [27] believed that water played an important role in the stabilization of the collagen triple helix molecular structure, and heating means the loss and reorganization of water molecules. Therefore, water molecules induce the structuring of the system within the collagen chain, thereby improving cohesion. Increasing the degree of cross-linking can improve the critical strain and pore distribution of the composite material, which has a trend of smaller size, but the degree of crosslinking of physical cross-linking is far less than that of chemical cross-linking [28]. Puyana et al. [29] compared the different effects of different cross-linking methods on the properties of chitosan/collagen composites. Studies have shown that the cross-linking of glutaraldehyde and 
genipin causes the composite to form a heterostructure with smaller pores (Fig. 1b, c), and the transglutaminase cross-linking appear to have unevenly small and long pores (Fig. 1d), while physical cross-linking results in fewer laminated structures and larger pores (Fig. 1e). Cross-linking changes the heterogeneity of the system, thereby improving the functionality of composite materials [28, 30]. Kaczmarek et al. [31] cross-linked chitosan and collagen with 1- (3-dimethoxypropyl)-3-ethylcarbodiimide hydrochloride (EDC) and N-hydroxysuccinimide (NHS). EDC and -COOH of collagen form unstable o-acyl isourea (OAU) intermediates. NHS stabilizes OAU and reacts with - $\mathrm{NH} 2$ of collagen to form NHS-collagen ester. The reaction of $-\mathrm{NH}_{2}$ of chitosan with NHS-collagenate increases the degree of cross-linking. The tensile stress can be increased by over 4.6 times than that of collagen. In addition, NHS and EDC also contribute to intramolecular crosslinking of collagen [24].

In addition, chitosan/collagen composites can also be crosslinked by inorganics. Tozar et al. [25] introduced hexagonal boron nitride ( $\mathrm{h}-\mathrm{BN}$ ) to make the material like plate-like layered structure and porous surface (Fig. 1f). The hardness and elastic modulus of composite materials increased with the increase of h-BN concentration, but as the concentration of h-BN continued to increase, the hardness and elastic modulus decreased. Türk et al. [32] and Zhang et al. [33] also obtained similar results in the studies of carbon nanotubes (MWCN $\mathrm{T})$ and graphene oxide. This may be due to the aggregation and exfoliation of nanofillers, so nanofillers that above a certain level will have a negative impact on mechanical properties [25, 32, 33]. The highly effective bacteriostatic effect of metal oxides on Staphylococcus aureus makes it widely used in collagen-based composites. When freeze-dried, $\mathrm{TiO}_{2}$ and chitosan/collagen form additional hydrogen bonds which act as a bridge between molecular chains to enhance the strength of the network structure [8]. As the temperature rises, collagen molecules move faster, which promotes self-assembly driven by electrostatic forces and further improves physical and mechanical properties. The synergistic antibacterial mechanism of chitosan $/ \mathrm{TiO}_{2}$ has not been fully figured out. Ibrahim et al. [34] speculated that the polycations of chitosan compete with $\mathrm{Mg}^{2+}$ and $\mathrm{Ca}^{2+}$ in the cell wall, and combined with the polyanions on the cell surface, causing the cell wall to lose its integrity. In this case, $\mathrm{K}^{+}$leaked from the cytoplasm, and the cells died when they have got contact with $\mathrm{TiO}_{2}$. After $\mathrm{K}^{+}$leaks, RNA and protein were released as well. $\mathrm{Xu}$ et al. [35] believed that the leakage of molecules such as o-nitrophenol and $\beta$-D-galactosyl would also increase the permeability of bacteria after exposure to $\mathrm{TiO}_{2}$. In addition to $\mathrm{TiO}_{2}$, nanomaterial composite chitosan/collagen such as $\mathrm{ZnO}$ [36] and $\mathrm{Fe}_{3} \mathrm{O}_{4}$ [37] can also increase the antibacterial rate to more than $90 \%$. Crosslinking can significantly improve the overall performance of chitosan/collagen composites, and has broadened application prospects in the fields of electroplating, textiles, and medical treatment.

\subsection{Chitosan/graphene composite material}

Chitosan / graphene composite materials have excellent antibacterial, film-forming, and adsorption properties,

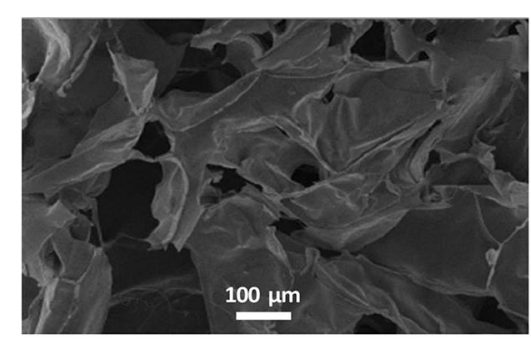

(a)

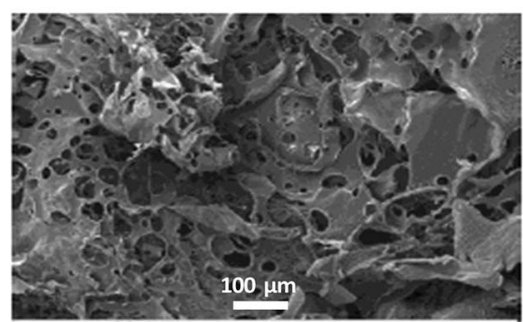

(d)

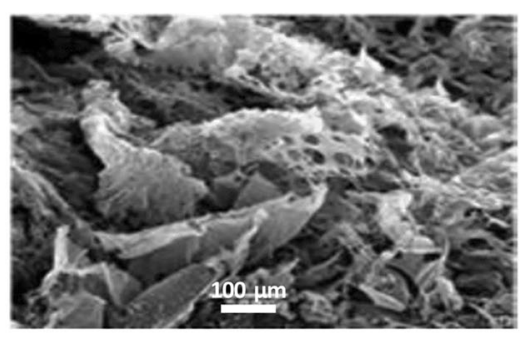

(b)

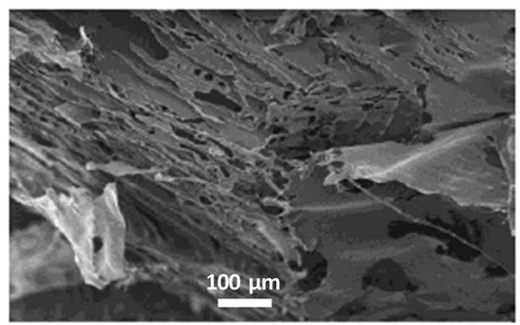

(e)

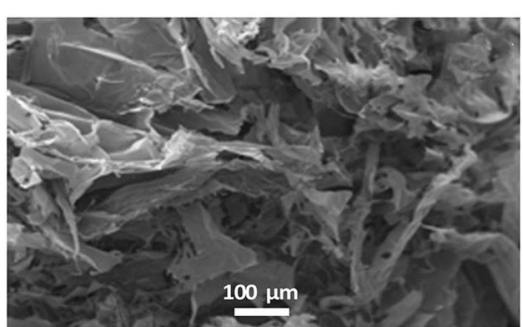

(c)

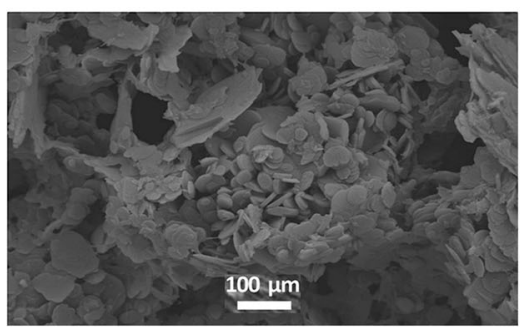

(f)

Fig. 1 Scanning electron micrograph of chitosan/collagen composites (a) Non crosslinked; b Glutaraldehyde; c Genipin; d Glutamic enzyme; e Physical cross-linking [29] Copyright 2019 International Journal of Biological Macromolecules; f h-BN [25] Copyright 2018 Applied Surface Science 
which makes chitosan / graphene composite materials likely to be the key to reduce the difficulty of tanning comprehensive wastewater treatment. Graphene (G) has large surface area and stable physical and chemical properties, while it is difficult to disperse but easy to agglomerate in polar solvents. The oxygen-containing functional groups of graphene oxide (GO) give the advantages of hydrophilicity and functional modification. The development of hydrophilic and biocompatible composites is the future direction of graphene-based composites [12]. GO has an epoxy functional group and chitosan has an amino group. Therefore, the reaction between GO and chitosan may be similar to the crosslinking and curing reaction of epoxy resin (Fig. 2a) which is nucleophilic substitution reaction [12, 38] Rozova et al. [39] found that when the content of GO was low, GO was contained in the matrix by chitosan in the form of a single filler, with low degree of crosslinking and obvious defects. In addition, the plane and sheet structure surface of GO made the chain segment of chitosan easier to slide. On the contrary, when the content was too high, the aggregation and peeling of GO would lead to the decrease of physical and mechanical strength (Fig. 2b, c, d) [33, 39]. Therefore, how to improve the dispersion and crosslinking degree of GO in chitosan is the key to improve the comprehensive properties of the composite.

Majidi et al. [40] and Wang et al. [41] found that the irregular shape of the inclusion area appeared on the rough surface of chitosan (Fig. 3), which indicated that the hydrogen and covalent bond of GO and chitosan resulted in the 3D structure of loose accumulation of CS/ GO. The strong electrostatic interaction of chitosan and GO forms ice crystals during freezing, and the viscous solution hinders the growth of ice crystals, resulting in many "micro strips" of 3D structure [42]. The "microstrip" structure is very stable, which may be the reason that the GO lamellae are evenly distributed in the chitosan matrix, avoiding the stress concentration caused by the GO aggregation, increasing the interface area of CS/ $\mathrm{GO}$, which is conducive to the stress transfer and concentration to GO lamellae, thus improving the structural stability of the material [43]. However, the agglomeration of CS/GO is more serious than that of GO dispersion, and the noncovalent modification of chitosan mainly by hydrogen bond does not enhance the stability of GO $[44,45]$. Further functionalization of GO can coat polyelectrolytes with opposite charges and connect them through intermolecular forces, which can better avoid the agglomeration of GO [44]. Xie et al. [46] and Lei

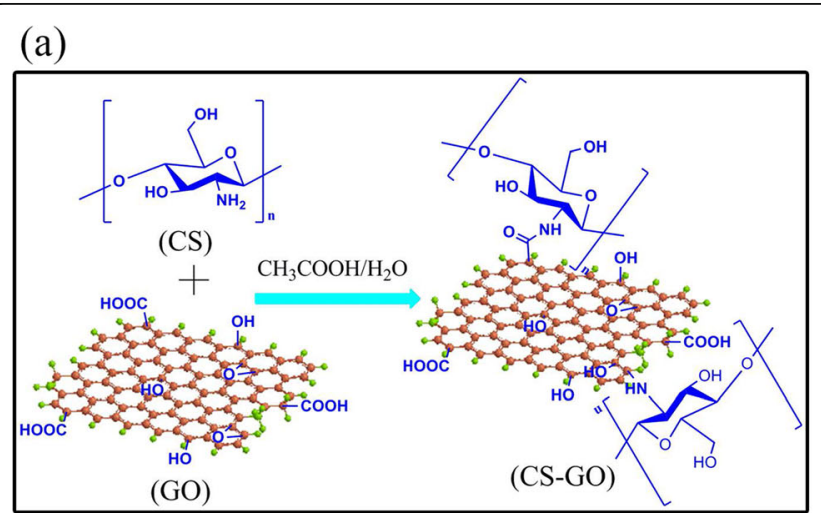

(c)

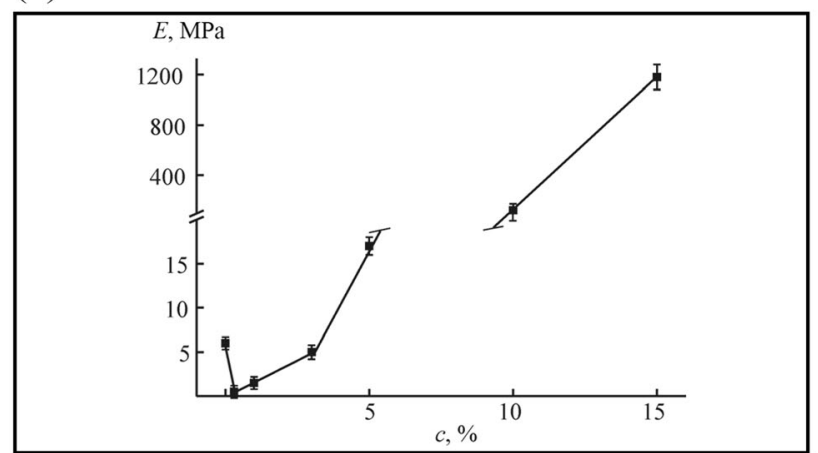

(b)

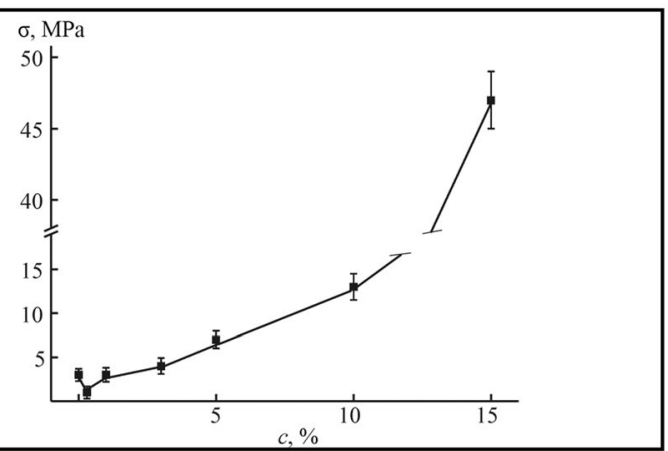

(d)

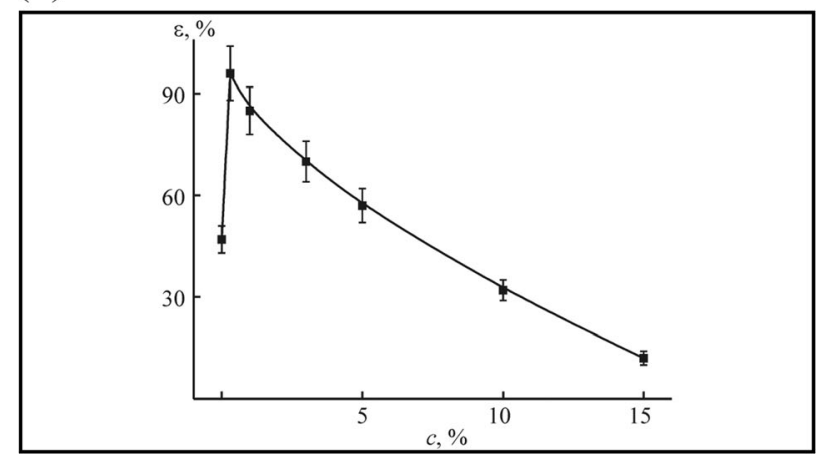

Fig. 2 a Cross-linking reaction during the formation of GO cross-linked CS composite [38]. Copyright 2017 Chemical Engineering and Technology. b Break strength, (c) elastic modulus, and (d) elongationat break vs. the content of GO in chitosan/graphene oxide composite systems [39]. Copyright 2019 Russian Journal of Applied Chemistry 

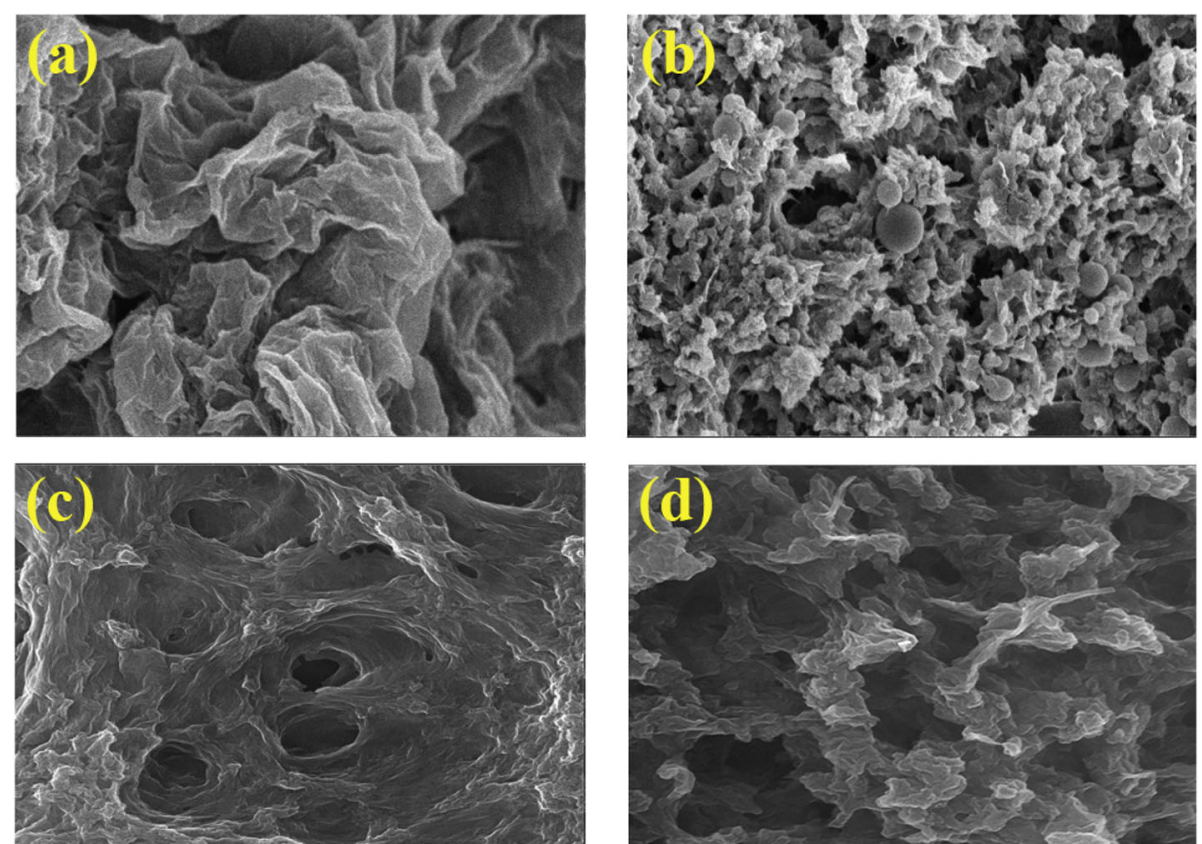

Fig. 3 FE-SEM micrographs of GO-CS nano-hybrids: a GO-CS pristine powder, (b) GO-CS microspheres, (c) GO-CS nano-fibrilar networks, smaller pores, (d) GO-CS nano-fibrilar networks, larger pores [40]. Copyright 2019 Carbohydrate Polymers

et al. [47] used dextran/chitosan and sodium alginate/ chitosan with negative charge to modify GO's function, and then deposited functional CS/GO by layer-by-layer self-assembly method. The composite did not show obvious agglomeration in physiological conditions or cell culture. Zhang et al. [45] found that $-\mathrm{COOH},-\mathrm{OH}$ and $-\mathrm{NH}_{2}$ modified $\mathrm{GO}$ and the $\mathrm{E}_{\text {ads }}$ of chitosan were -1.23 $\mathrm{eV},-0.4 \mathrm{eV}$ and $0.84 \mathrm{eV}$ respectively (Fig. $4 \mathrm{a}-\mathrm{c}$ ). The influence of $-\mathrm{OH}$ and $-\mathrm{NH}_{2}$ was weaker than that of $-\mathrm{COOH}$, so it could enhance the interface interaction
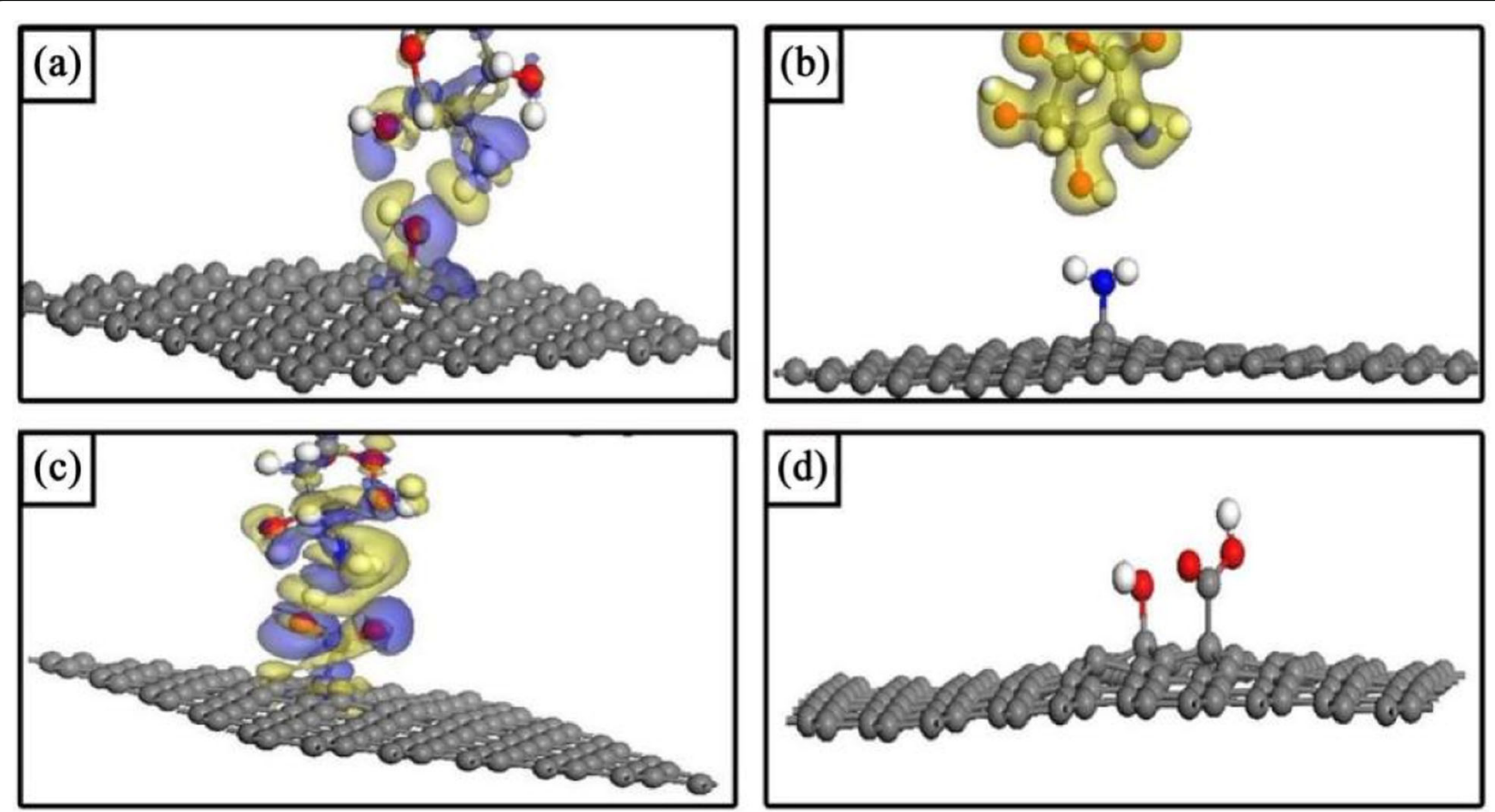

Fig. 4 Interaction mechanisms of chitosan unit and functionalized GO: a chitosan unit on -OH modified GO; b chitosan unit on - $\mathrm{NH}_{2}$ modified $\mathrm{GO}$; c chitosan unit on - $\mathrm{COOH}$ modified GO; d - $\mathrm{COOH}$ and -OH modified GO [45]. Copyright 2016 Applied Surface Science 
between GO and chitosan. Pan et al. [48] discovered that the interaction between chitosan and GO increased with the increase of $-\mathrm{COOH}$ content and decreased with the increase of $-\mathrm{NH}_{2}$ content. The interaction between chitosan and functionalized GO can be regulated by the different combinations and contents of functional groups in GO. When chitosan was combined with the functionalized $\mathrm{GO}$ of $-\mathrm{COOH}$ and $-\mathrm{OH}$, the interaction force was the strongest (Fig. 4d) [45]. Therefore, controlling the content of $\mathrm{GO}$ functional group can regulate the interaction between functionalized GO and chitosan, so as to improve the dispersion of GO and the stability of CS/GO $[44,45,48]$.

The oxidation degree of graphene determines the hydrophilicity, charge property and oxidation area, which directly affects the performance of CS/GO. Kosowska et al. [49] used different methods to reduce GO and prepare reduced graphene oxide (RGO). It was found that L-ascorbic acid has the strongest reducibility and dispersion. The reduction of GO in alkaline condition enhanced the electrostatic repulsion between the layers of RGO, thus improving the dispersion stability of RGO in chitosan matrix. The nucleation of nano fillers in the chitosan matrix can effectively improve the crystallinity of the composite, the reduction of RGO increases the specific surface area, and the electrostatic interaction enhances the ordering of the polymer structure compared with GO [50]. In addition, the water contact angle of chitosan is $109.91 \pm 2.35^{\circ}$, while the wettability of chitosan is only increased by $7^{\circ}$ after GO modification, which may be caused by the low content of GO on the surface of chitosan, and the wettability of the composite cannot be determined by the hydrophilicity of GO [51]. Different from GO, RGO has greater visibility on the surface and more significant influence on the wettability. The surface of CS/RGO reduced by $\mathrm{L}$-ascorbic acid is completely hydrophilic. This is due to the parallel arrangement of RGO on the surface of chitosan, forming a surface with micro scale roughness [49]. The strong association between -OH of GO and $-\mathrm{NH}_{2}$ of chitosan makes the composite ductile and brittle, and the young's modulus can be increased by more than $35 \%$ $[49,51]$; Because of the agglomerations of RGO, the young's modulus decreases, and RGO/CS samples are soft and easy to bend without cracking [49]. CS/GO is the advantage superposition of biological composite materials and nano materials, which makes the structural parameters and composite effects of materials fully play a role.

\subsection{Chitosan/tannin acid composite material}

In the ancient times, humans used tannin acid to tan leather, this is the earliest people began to recognize and apply tannin acid. Tannin acid is a kind of polyphenolic compound with carbohydrate (such as glucose) as the core whose molecular weight is $500-3000$. It is esterified by phenolic acid (such as gallic acid) (Fig. 5a) [5, 52]. Qin et al. [54] speculated that tannin acid has high stability of self-assembly, which was related to the high rigidity of tannin acid. The - $\mathrm{OH}$ of tannin acid and the $-\mathrm{NH}_{2}$ of chitosan are mainly hydrogen bonded, and there are van der Walls forces as well (Fig. 5b) [5, 54]. Tannin acid plays the role of crosslinker in chitosan matrix. Crosslinking improves the tensile strength, reduces the elongation at break, and improves the mechanical properties to some extent, it can also enhance the antibacterial properties of chitosan-based composite materials [55]. However, the surface hydrophobicity of the composite was improved after tannin acid and chitosan were compounded, which indicated that the polar group of tannin acid was located below the surface of the composite, forming hydrogen bond association [54]. When the hydrated conformation of chitosan/tannin acid is destroyed, the hydrophobicity will be further improved [56]. Sionkowska et al. [53] used UV to degrade chitosan/tannin acid composite (Fig. 5c). Photodegradation promoted the formation of hydroxyl and carboxyl groups, increased polar components, decreased dispersion components and enhanced hydrophilicity. Photodegradation also destroyed the hydrogen bond between chitosan molecules, absorbed more water molecules in the structure, and increased the water content. However, water may affect the photodegradation of tannin acid [57]. In addition, small molecular plasticizers such as glycerol [56] can also improve the hydrophilicity of chitosan/tannin acid.

Because of the hydrophobic interaction between aromatic ring of tannin acid and hydrophobic region of polymer chain segment, tannin acid can be used to improve the stability, mechanical properties and bacteriostasis of polymer materials $[58,59]$. Rubentheren et al. [58] used tannin acid to crosslink chitosan and cellulose (NCC), and the cross-linking could form a more stable network between CS and NCC, and significantly improved the physical and mechanical properties. NCC can effectively transfer stress and act as a barrier of stress propagation at the interface of chitosan [60]. At the same time, the high crystallinity of NCC improves the tensile strength and Young's modulus of CS/NCC [61]. After heat treatment, the physical and mechanical strength is further improved, which is caused by the improved crosslinking degree of CS/NCC [58]. Thakhiew et al. [62] believed that the increased crosslinking degree by heat treatment can make the composite form a highly dense structure, thus inhibiting the formation of crystal structure. The compact structure can increase tensile strength and stiffness, while the elongation is reduced by the energy dissipation and the mobility limitation of the 

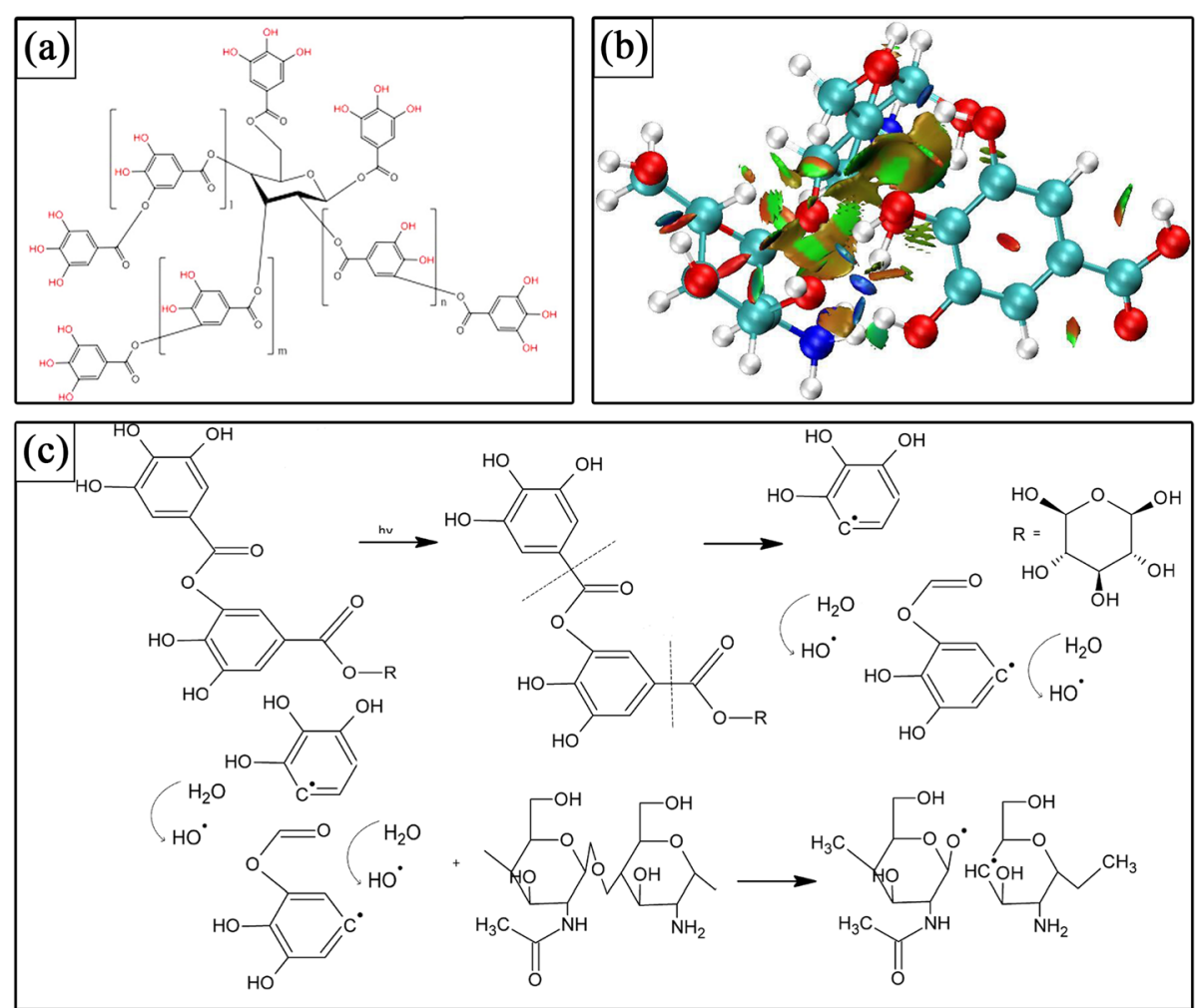

Fig. 5 a Tannin acid molecular structure [52]; Copyright 2013 Carbohydrate Polymers. b Surface action of the chitosan/tannic acid [5]; Copyright 2019 Chemical Physics. c Mechanism of chitosan and tannic acid photodegradation [53]. Copyright 2015 Journal of Photochemistry and Photobiology B

molecular chain $[56,58,62]$. Wettability and hydrophilicity are important factors of bacterial adhesion. Bacterial adhesion with medium wettability and hydrophilic material surface is better than that with super wettability and super hydrophilic surface, among which when NCC water contact angle is $26.4^{\circ}$, and wettability and hydrophilicity are strong [63]. Huang et al. [59] alternately deposited chitosan/tannin acid and chitosan composite membrane on NCC substrate through layer by layer selfassembly. When the outermost layer was chitosan, the water contact angle decreased, and when chitosan/tannin acid was deposited, it increased. Therefore, the hydrophilicity and wettability of the composite can be adjusted by changing the number of deposition layers of chitosan/tannin acid and chitosan. The antibacterial activity increases with the raise of the number of layers, and the antibacterial rate of the composite material to Staphylococcus aureus is over 99\%, which may be due to the fact that tannin acid can directly combine with the peptidoglycan layer of Gram-positive bacteria and play a bacteriostatic role $[59,64]$. In addition, the lipopolysaccharide on the outer membrane is negatively charged, and the positively charged chitosan can also play a role of biological adhesive [65]. However, the peptidoglycan layer of Gram-negative bacteria is thin and can't effectively combine with chitosan/tannin acid, and the antibacterial rate of Gram-negative bacteria to Escherichia coli is low $[64,66]$. In addition, tannin acid can also be used in cross-linked chitosan/collagen [66], chitosan/ gelatin [67], chitosan/hyaluronic acid [68] and further be applied in food packaging and wound dressing etc.

\subsection{Chitosan/polyethylene glycol composite material}

Polyethylene glycol (PEG) is a kind of amphiphilic biomaterial, which has both hydrophilicity and flexibility, and is widely used in the graft modification of polymers [6]. After PEG modification, the solubility of chitosan is increased, maintaining the molecular structure and length of chitosan. At the same time, chemical modification and reaction can be carried out on the side chain of chitosan [69]. Locharoenrat [70] found that in the form of hydrogen bond, oligopeg was combined to the hydroxyl and amino groups of chitosan as well as ether group, while in the high polymer CS/PEG system, the degree of crosslinking was weak, and chitosan was easy to form intramolecular hydrogen bond. The low degree of cross-linking improves the spacing and size of polymer network, and the high degree of cross-linking limits the free movement of chain segments [71]. The amorphous phase of chitosan destroys the crystallinity of the 
polymer and produces irregular structure, which helps the effective water diffusion into the polymer network [6, 71]. Mohamed et al. [72] modified the carboxylation function of chitosan to improve the crosslinking degree and hydrophilicity of the composite. A similar conclusion has been obtained from the introduction of amino methyl group on chitosan by Boles et al. [69], which showed that the intrinsic viscosity of the composite was lower than that of the unmodified composite. The solubility of chitosan in neutral condition was significantly improved by trimethylation and carboxylation [69, 72]. Jintapatanakit et al. [73] speculated that the molecular weight and intrinsic viscosity of chitosan would also be reduced by the chain break during the modification. Carboxylated chitosan can effectively coat Gram-negative bacteria, thus destroying the barrier performance of bacterial outer membrane [69]. In addition, quaternized chitosan derivatives, grafted antibacterial materials (such as aniline tetramer) and aschitosan derivatives have synergistic antibacterial effect with vancomycin and aracaine [69, 73, 74].

PEG modified chitosan can occur on amino group and also on C-6 hydroxyl group. However, the modification on amino group will change the skeleton structure of chitosan, thus losing some physical and chemical properties and biological activity [75]. Bratskaya et al. [76] was grafted onto chitosan C-6 hydroxyl group through two glycidyl ether to obtain a porous low temperature gel with high stability. The concentration effect of chitosan and diglycidyl ether makes them maintain high crosslinking degree and mechanical properties at low temperature. At the same time, the modification of C-6 hydroxyl provides the possibility for the further target modification of chitosan amino group, which makes the material have specific biological properties. PEG can enhance the biocompatibility of chitosan and its derivatives, reduce the biological toxicity, and is widely used in peptide drugs, drug delivery and functional materials.

\section{Application of chitosan-based composites in the leather industry}

\subsection{Leather auxiliaries}

Natural leather is made of animal fibers, and has good breathability, water permeability and sweat absorption. However, when a large amount of protein, tannin, animal fats and other tanning agents, fillers, fatliquors, etc. are added, sufficient nutrients for microbial reproduction are provided during the leather production and processing process. Also, the imperviousness of natural leather to washing makes it easy to cause the residue of dirt such as sweat, which corrodes the leather and harms the user's health [19]. Therefore, bacteriostatic agents are often added during leather production and processing to prevent leather degradation. However, bacteriostatic agents commonly used in the tanning industry (such as halogenated phenols) are harmful not only to humans but also the environment whose use has been restricted or even prohibited [77]. According to the relevant standards of leather and leather chemicals in the EU, the United States, China and other places, such as ZDHC MRSL V2.0, the fungicides for leather and leather chemicals are mainly limited to o-phenylphenol, permethrin, chlorophenols. Taking chlorophenols as an example, such compounds have environmental stability, bioaccumulation, and biotoxicity. Chlorophenols can interfere with the synthesis, release, transport, assembly and metabolism of the source hormones, thereby affecting the stability of the internal environment of the collective, reproduction, development and behavior. Chlorophenols has a very toxic effect on embryo development. In areas where chlorophenols is seriously exceeded, embryo mortality and deformity rates have increased significantly. Chlorophenols can also induce oxidative stress in organisms, leading to oxidative damage. In addition, chlorophenols will also cause the chromatid to break, deviate from the center, form a ring and aneuploid structure, which indicates that chlorophenols also has certain genotoxicity [19, 77]. Therefore, it is extremely urgent to develop composite materials with low biological toxicity and strong antibacterial properties. The excellent antibacterial and bacteriostatic properties of chitosan and its derivatives can be used as high-efficiency bacteriostatic agents for leather products, which can slow down the spoilage of raw material skin, thereby reducing the amount of preservatives and fungicides used in production. The amino protonation of chitosan can adsorb negatively charged bacteria, so that the cell wall is dissolved, the cell membrane is broken by osmotic pressure, the cytoplasm flows out, and the bacteria are inactivated to death. In addition, chitosan can also interfere with the work of DNA polymerase and RNA polymerase, thereby inhibiting the reproduction of bacteria $[33,34]$. When chitosan is combined with other antibacterial active substances (such as graphene, tannin, and polyethylene glycol), the synergistic antibacterial effect is enhanced. The strong interaction between chitosan and collagen makes it have a certain tanning property, but due to the long molecular chain of collagen fiber and low water solubility, the interaction with chitosan is weak and it is easy to detannify. Therefore, functional groups with higher activity are grafted on chitosan to improve the binding ability of chitosan and collagen. Lv et al. [78] copolymerized chitosan with methacrylic acid and acrylamide, and this composite material was used in the leather retanning and filling process to improve physical and mechanical properties. The thickening rate was also improved compared to acrylic retanning. This shows that the graft modification helps to improve the combination of chitosan and collagen fibers, so that the 
structure of collagen fibers is more compact. The positively-charged chitosan has strong hydrogen bonding with the tannin acid hydroxyl group, which can also be used to improve the mechanical properties of vegetable tanned leather [79]. The tannin extract molecule also acts as a small molecule cross-linking agent in the threephase system of chitosan / collagen / tannin extract. Through the hydroxyl groups on the tannin extract molecules, the combination of chitosan and collagen is improved, so that the chitosan is fixed in the collagen fibers of the leather, which gives the leather excellent antibacterial properties. In addition, the protonation of the hydroxyl and amino groups of chitosan is reduced under acidic conditions. During dyeing, the coulomb repulsion between collagen fibers and anionic dyes is reduced, thereby improving dyeing performance $[79,80]$. Islam et al. [80] showed that chitosan can introduce more active sites, which is beneficial for dye binding. In addition, the synergistic effect of chitosan and tannin can make active hydrogen interact with free radicals and convert them into stable compounds. The antibacterial rates against E. coli and Staphylococcus aureus can reach more than $99.55 \%$ and $98.66 \%$, respectively $[80,81]$. Apart from that, we all know that gram positive bacterium S. aureus is made of thick layer of peptidoglycan, compared to gram negative bacterium E.,it is more resistant to chitosan [82]. The reason why chitosan/tannic acid composites have antibacterial properties is mainly because of the electrostatic interaction between the positively charged $\mathrm{NH}_{3}{ }^{+}$groups of chitosan and the negatively charged residues in the bacterial cell membrane, which makes the cell permeability changes and osmotic imbalances [64]. Furthermore, intracellular electrolytes and low-molecular-weight proteins, such as nucleic acids, glucose, dehydrogenase, etc., have leaked due to the peptidoglycans present on the amino hydrolysis membrane, which hinders normal metabolic processes and leads to cell apoptosis $[65,66]$.

Chitosan and its derivatives can be used as highefficiency bacteriostatic agents in tanning in watersoaking, tanning, and retanning sections, and also as anti-fungal agents for leather. A large amount of enzyme preparations are used in leather degreasing, softening, softening, fatliquoring and finishing, but the residue of enzyme preparations will cause mold to breed in the storage and use of leather. In addition, the leather contains a lot of skin collagen and many nutrients necessary for fungal growth and reproduction. Therefore, once the mold spores in the air fall on the leather, they can obtain rich nutrition. Under the proper temperature and humidity, the fungus is easy to grow and reproduce. When the fungus molds, in addition to making the leather emit an unpleasant odor, it will also promote the aging of the leather and make it tarnish, moldy and brittle, so as to reduce the physical and mechanical properties At present, there are large-scale application examples of modified enzyme preparations such as chitosan and crown ether / chitosan, nano silver / chitosan in leather chemicals. Chitosan has excellent biocompatibility and stability, and does not inhibit the activity of enzyme preparations, which can greatly delay the erosion of microorganisms on gray skin, softened skin, wet blue leather, etc. However, due to the strong antibacterial effect of chitosan, when all the mold inhibitors and fungicides are replaced, the loss of activated sludge is more obvious. Therefore, it is still necessary to study the interaction force of chitosan / collagen in depth, enhance chitosan in the fixation effect in the skin collagen fiber, reduce the content of chitosan in the water body, thereby promoting the application of chitosan-based antibacterial and antifungal materials in the leather industry. The application of chitosan in the production of raw leather to billet leather is mainly in the form of "antibacterial and anti-mildew additives". In addition, it can also be used in the tanning and finishing section by utilizing the excellent film forming properties of chitosan to give leather excellent antibacterial properties. Fernandes et al. [82] applied 1\% chitosan to the rough leather by roller coating and spray coating, and the leather samples showed a more uniform and smooth surface (Fig. 6a,b). At the same time, the antibacterial activity of the sample against Staphylococcus aureus and E. coli was more than $90 \%$, the antibacterial mechanism of chitosan may be the interaction with negatively charged microbial cell membranes leading to the leakage of proteins and other components [34, 35]. Chitosan also acts as a chelating agent, selectively binding trace metals, thereby inhibiting toxin production and microbial growth [84]. At the same time, chitosan can also activate the defense process in host tissues, acting as a waterbinding agent to inhibit the production of enzymes [85]. In addition, chitosan can penetrate the cell membrane of microorganisms and interfere with RNA and protein synthesis [86]. However, the spray sample only has a smaller inhibitory area and a lower bacteriostatic effect. Increasing the amount of chitosan can effectively improve this problem, but when the spraying amount is too large, the leather surface appears stains and bright spots [82]. In addition, the polymer also has a certain healing function, as can be seen from Fig. $6 \mathrm{c}$, the pores on the leather surface are filled. From the meat surface layer, it was observed that the polymer coating adhered evenly to the collagen fibers (Fig. 6d) [83]. Although the chitosan antibacterial coating has certain bactericidal advantages [87], the concentration of chitosan is relatively low during coating, and it is difficult to achieve theoretical values in practical applications. To solve this problem, Luo et al. [83] grafted PEG to chitosan (Fig. 7a), 

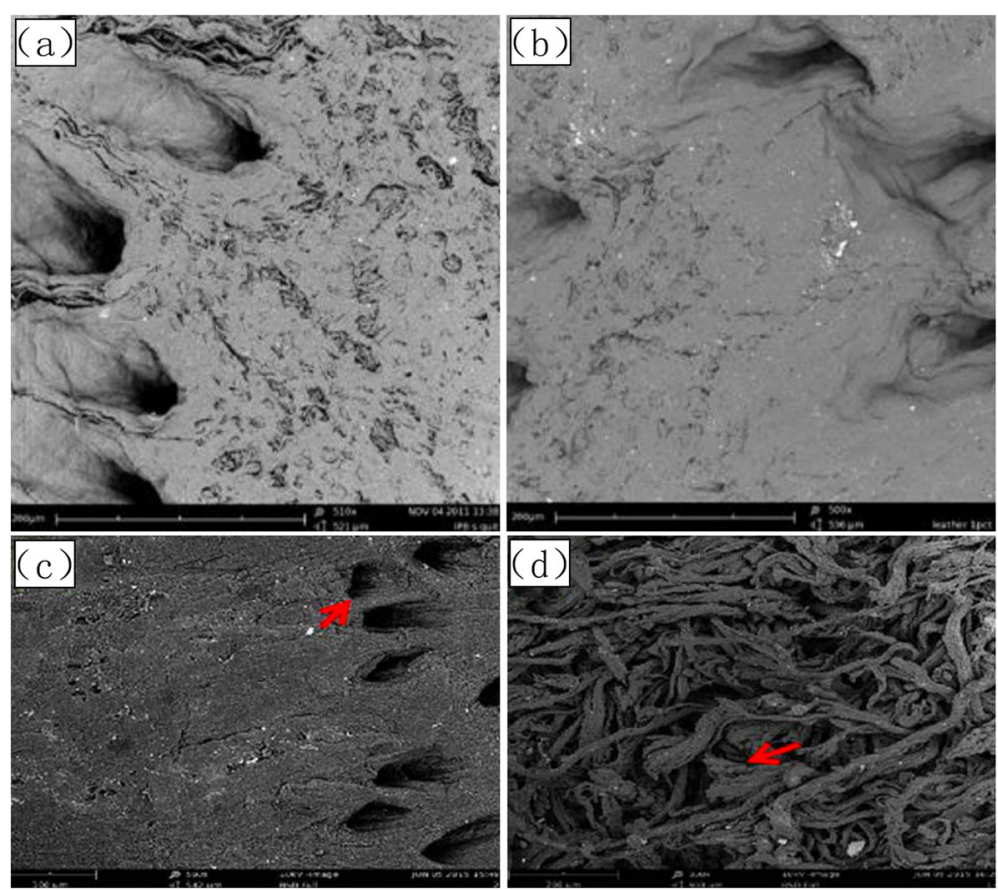

Fig. 6 SEM image of (a) non-coated leather; b 1\% chitosan coated leather [82] Copyright 2013 Carbohydrate Polymers; c PEG/CS coated leather of grain layer; d PEG/CS coated leather of flesh layer [83] Copyright 2016 Journal of Applied Polymer Science

making it have good resistance to bacterial attachment and accelerated release of dead cells (Fig. 7b). Modification of PEG improves hydrophilicity, which can effectively improve antifouling properties. After alcoholization, the water solubility of the chitosan/polyethylene glycol composite was improved, and its copolymer chain in the bacterial solution was more easily stretched. Therefore, more amino groups in the composite material can contact the bacteria, leading to the death of the bacteria, so the composite material has more excellent antibacterial properties $[69,88]$. The chitosan/polyethylene glycol composite material still had more than $90 \%$ antibacterial activity against 512 times diluted bacterial culture solution, and the antibacterial activity of chitosan solution at the same concentration against 32 times diluted bacterial culture solution has been reduced to less than $90 \%$ [83]. When the chitosan coating is fixed on the surface of the substrate, dead cells will cover the active surface after a period of time, resulting in a decrease in the bacteriostatic rate. Their contact killing activity will be reduced to some extent, which may be due to Proliferation is hindered [88]. Liu et al. [89] polymerized nanosilver on chitosan with chitosan/PEG composites (Fig. 7c), and loaded nanosilver through contact and released mechanisms to enhance its antibacterial activity (Fig. 7d). This is due to the dual bactericidal effect of chitosan and Ag. Copolymer chains have greater stretching ability than chitosan, and PEG's unique bacterial resistance and release ability make it easier to contact with bacteria and cause them to die [83, 90]. Among them, the PEG component can prevent bacteria from adhering to the coating surface, and chitosan can kill the bacteria through contact, and can continuously inhibit the growth of bacteria. However, for chitosan/PEG/Ag coatings, the significant improvement in antibacterial properties may be attributed to the resistance of bacteria to PEG, which kills cells by contact. $\mathrm{Ag}^{+}$- based releasebased antibacterial properties, the sugar-based bactericidal function, these three work together [91, 92]. The polymer releases killed bacteria from the coating by simple water washing, making it reusable [90].

\subsection{Water treatment}

Tannery wastewater is one of the most difficult industrial wastewater to treat. It is characterized by complex components, high COD, and high chroma, and contains a lot of harmful substances such as protein, sulfide, inorganic salt, heavy metal chromium [93]. In tanning process, chrome tanning agent is the most commonly used metal tanning agent, but heavy metal chromium is recognized as a strong carcinogen by the International Anticancer Research Center. China has strictly controlled the discharge of chromium-containing wastewater. Chromium ions in tannery wastewater exist in the form of Cr (III) and Cr (VI), but due to the complex water quality, the removal effect is not good. The removal of Cr (VI) has become a difficult part in the treatment of comprehensive wastewater. Both chitosan and 


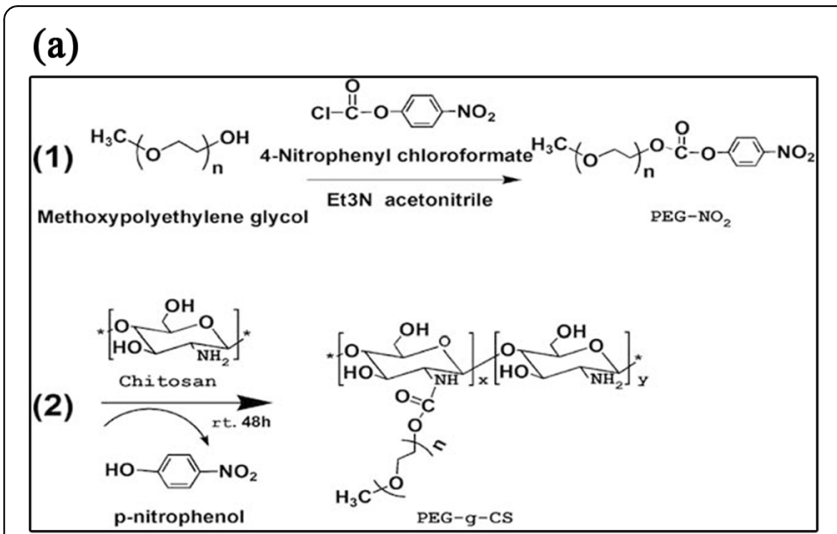

(c)

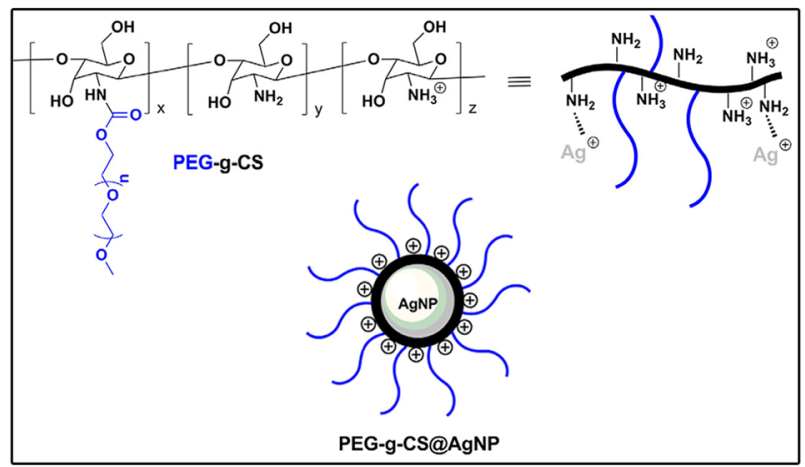

(b)

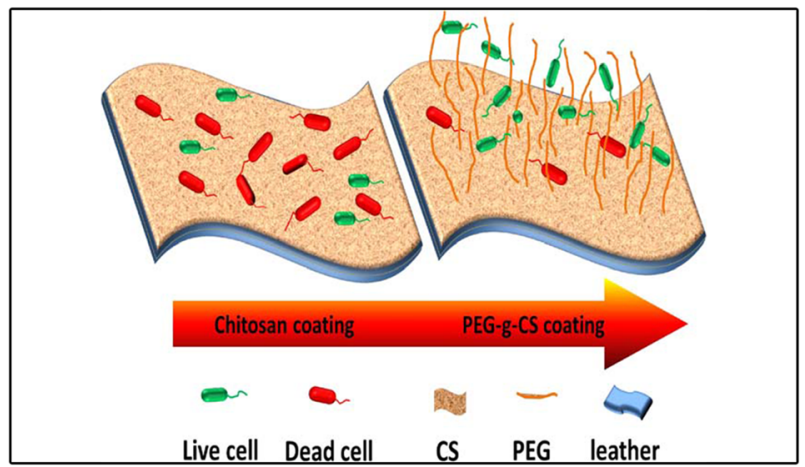

(d)

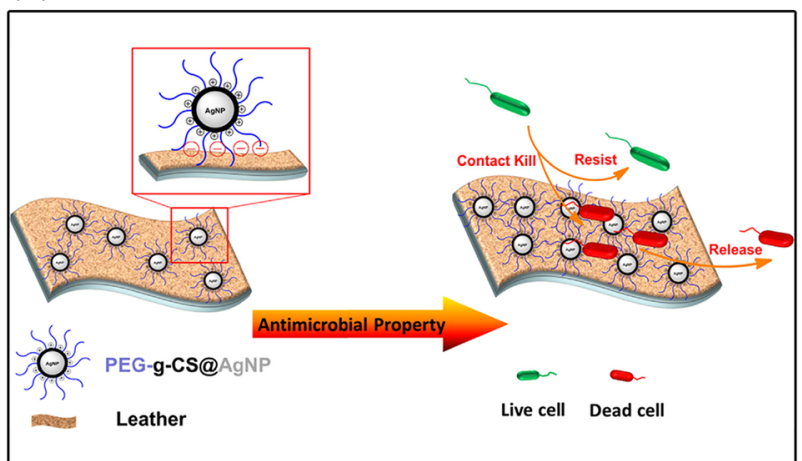

Fig. 7 a Synthetic route of PEGylated Chitosan; b PEG/CS coating exhibited more efficiently antimicrobial property than that of chitosan coating, due to the anti-adhesive PEG chains [83] Copyright 2016 Journal of Applied Polymer Science. (c) Schematic illustration of PEG/CS stabilized Ag; $\mathbf{d}$ Schematic construction of PEG/CS@Ag coating onto the leather surface and its multi-function antibacterial mechanism [87] Copyright 2017 Journal of Colloid and Interface Science

GO are highly efficient adsorption materials. Synergistic adsorption can reduce GO aggregation and increase specific surface area, and can effectively increase active adsorption sites, thereby improving adsorption performance [94]. However, both of them are hydrophilic materials, which are difficult to separate from the water phase after adsorption, which will cause secondary pollution of water. Therefore, magnetic particles can be carried on CS/GO, and can be recovered by magnetic separation after their adsorption (Fig. 8a, b) [95, 97-99]. Subedi et al. [97] synthesized $\mathrm{CS} / \mathrm{GO} / \mathrm{Fe}_{3} \mathrm{O}_{4}$ by a solvothermal method. Studies have shown that the greater the protonation of $\mathrm{H}^{+}$ions on the surface of the adsorbent, the stronger the electrostatic attraction between the adsorbent and the negatively charged chromate ions. When the $\mathrm{pH}$ value is increased, the degree of protonation of the primary amino group is weakened, the hydroxyl ion adhesion is enhanced, the negative charge on the adsorbent surface and the anions are mutually repelled, so the adsorption capacity is weakened; when the $\mathrm{pH}$ value is too low, $\mathrm{Cr}$ (VI) forms $\mathrm{Cr}_{4} \mathrm{O}_{13}{ }^{2-}$ and $\mathrm{Cr}_{3} \mathrm{O}_{10}{ }^{2-}$, which is difficult for ion exchange adsorption (Fig. 8c, d) [95]. The magnetic $\mathrm{Fe}_{3} \mathrm{O}_{4}$ is stable and easy to separate after being carried. Even if after 4 times of reuse, the adsorption capacity can be restored to more than $95 \%$ of the original saturated adsorption capacity [95, 97]. When Le et al. [99] studied the adsorption of $\mathrm{Ni}$ (II), they found that in addition to binding to hydroxyl groups, $\mathrm{Ni}$ (II) could also complex with $\equiv \mathrm{FeOH}$ to adsorb on $\mathrm{Fe}_{3} \mathrm{O}_{4}$ particles. In addition to exploring the physical parameters of magnetic CS/GO, it is also necessary to explore the characteristics of nanomaterials and biotoxicity in environmental systems. Samul et al. [100] found that the lower the GO/chitosan@ $\mathrm{Fe}_{3} \mathrm{O}_{4}$ composite concentration, the stronger the biocompatibility. They cultured A549 cells at different concentrations and measured their activity after $24 \mathrm{~h}$ of incubation. The results show that when the concentration is $50 \mu \mathrm{g}$, its activity is about $53.7 \%$, and when the concentration is $100 \mu \mathrm{g}$, the activity is about $44.8 \%$.However, when the concentration was increased to $150 \mu \mathrm{g}$, the percentage of living cells decreased sharply, at only $32.97 \%$, and also pretty low at $5.47 \%$ when it is $200 \mu \mathrm{g}$.

The EU's current ZDHC Wastewater Guidelines Version 1.1 for tanning and upstream and downstream industries, as well as China's relevant national standards, have strictly limited the total amount of microorganisms 

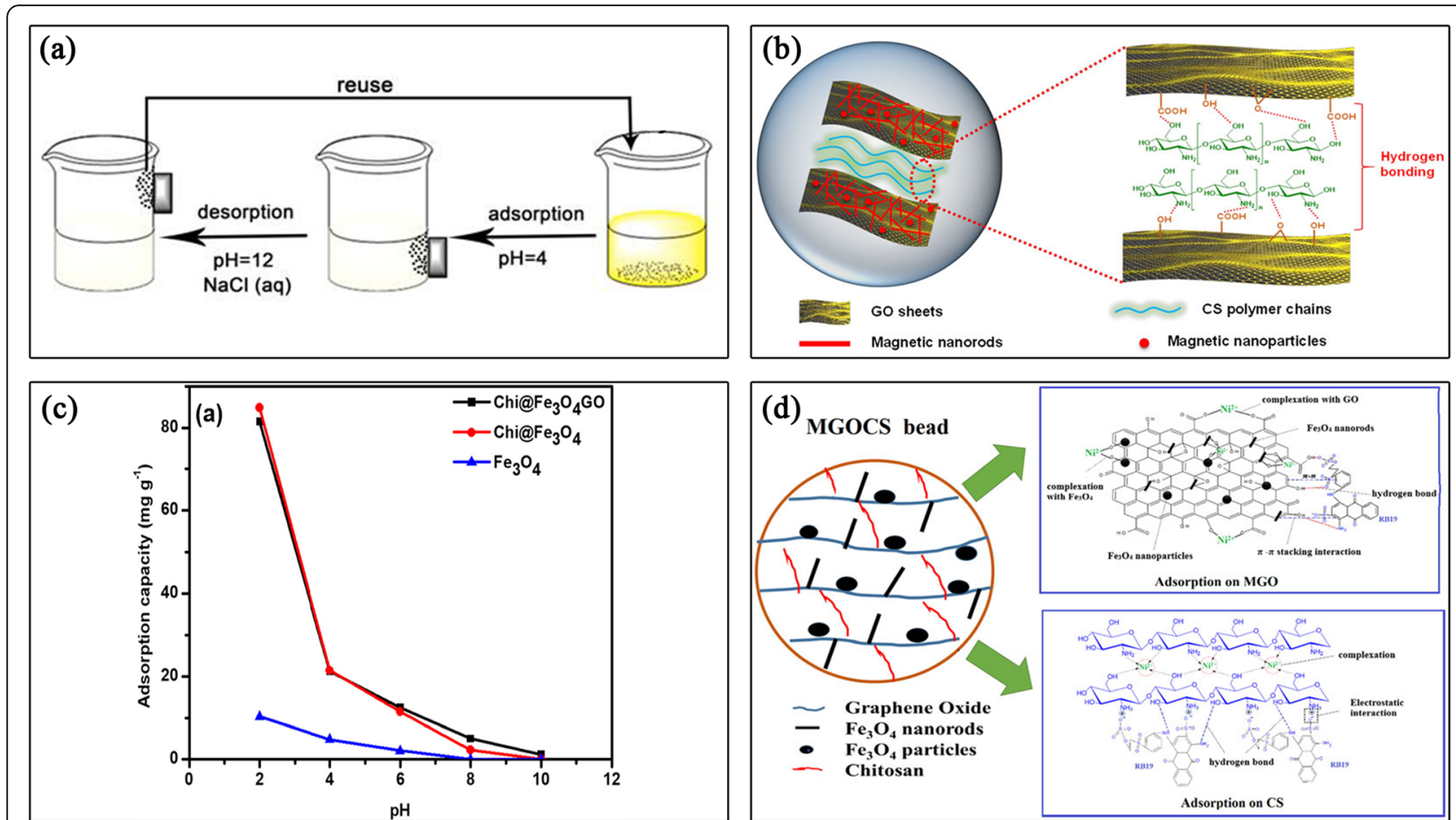

Fig. 8 a Principle of magnetic based CS/GO composite materials absorption and desorption [95] Copyright 2018 Bioresource Technology; b Proposed adsorption mechanisms of methylene blue onto CS/GO [96] Copyright 2019 International Journal of Biological Macromolecules; c Effect of $\mathrm{pH}$ on $\mathrm{Cr}(\mathrm{VI})$ adsorption macromolecules; $\mathbf{d}$ Effect of adsorbent dosage on removal efficiency and adsorption capacity of $\mathrm{Cr}(\mathrm{VI})$ onto different adsorbents [97] Copyright 2019 International Journal of Biological

in wastewater. The current control of microorganisms in wastewater includes E. coli, Staphylococcus aureus, Pseudomonas aeruginosa, Candida, etc. Microorganisms in the water body will secrete a lot of mucus, which will adhere to the surface of the equipment and pipelines and cause serious corrosion after deposition. At the same time, it will isolate the drug from the metal, so that the agent can not exert the corrosion and scale inhibition efficiency of its application [13]. In addition, the excessive release of microorganisms from the water into the environment will cause inestimable damage to the ecosystem [33]. In traditional water treatment, oxidants such as chloride, hydrogen peroxide and ozone are often used to kill microorganisms. Such oxidants are extremely water-soluble and often cause chemical residues in the water system, making various of anti-bacterial microorganisms appear. At the same time, chlorinecontaining oxidants will also react with trace organic substances in water to generate carcinogenic, teratogenic and mutagenic by-products such as trihalomethane, which is a serious danger to human and environmental health [41]. Therefore, there is an urgent need to develop a non-toxic, chlorine-free, recyclable and highly effective antibacterial water treatment material. Chitosan can significantly inhibit the growth of bacteria, although their inhibitory effects vary with molecular weight and bacterial species $[33,34]$. This may be due to the mechanism of cell membrane dispersion, when positively charged chitosan interacts with negatively charged proteins and phospholipids in microbial cell membranes, resulting in leakage of cytoplasmic contents [101]. Another possible reason is that chitosan oligosaccharides can penetrate into the nucleus and interfere with the RNA transport mechanism, thereby interfering with protein synthesis [102]. Consistently, the GO-chitosan layer shows significant antibacterial activity, and the antibacterial activity of the layer can be increased by increasing the content of graphene, which is consistent with the previously reported antibacterial properties of graphene materials. The bacterial inhibition on the surface of the layer can be attributed to both membrane and oxidative stress [103], as well as the direct contact of the sharp edges of the GO slices (vertically arranged slices) with the bacterial cell membrane. In fact, $S$. aureus as Gram-positive bacteria is more sensitive to direct contact interactions of graphene sheets than Gram-negative bacteria [104]. Therefore, increasing the surface roughness can enhance antibacterial activity [105].

Jiang et al. [106] studied the antibacterial properties of chitosan, graphene oxide, $\mathrm{Fe} 3 \mathrm{O} 4$, and composites with E. coli as a model (Fig. 9a), and the results showed that 
the antibacterial activity of the composites was better than any of a single one. Cortinez et al. [109] found that the extra outer membrane present in E. coli made it more resistant to the biological toxicity of GO, which was consistent with the report by Akhavan et al. [105]. As recently reviewed, GO's antimicrobial behaviorarises is caused by the contact with nanoparticles from the bacteria disruption under different mechanisms [110]. One mechanism is due to bacterial membrane stress, and the other is due to oxidative stress. Nevertheless, the antibacterial activity of pure chitosan membrane is still the highest, since its polycationic structure can electrostatically interact with anionic components on the surface of bacteria [111]. However, despite the high antibacterial properties of chitosan, it does not add any synergy to the GO structure. In addition, Sreeprasad et al. [107] synthesized different materials (such as natural lactoferrin (NLf) or NLf protected gold clusters (Au@NLf) and/or chitosan) in GO/RGO to synthesize multiple functional composite materials (Fig. 9b). They found that the multifunctional composite material has higher antibacterial activity than GO/RGO due to the synergistic effect of the material combination. Wang et al. [108] synthesized a $\mathrm{ZnO} / \mathrm{GO}$ complex, and they found that the antibacterial activity of the $\mathrm{ZnO} / \mathrm{GO}$ complex was mainly due to their synergistic effect (Fig. 9c). Ma et al. [112] also reported that silver-modified graphene oxide nanoplatelets exhibited higher antibacterial activity against $E$. coli due to the synergistic effect [35] (Fig. 9d).

In addition to heavy metal adsorption and antibacterial properties, magnetic chitosan/GO also has broad application prospects in dye adsorption. Taking a typical anionic dye disperse blue 367 as an example, unlike the adsorption of heavy metals, anionic dyes are adsorbed on the surface of the composite material through electrostatic interaction with protonated $-\mathrm{NH}_{3}{ }^{+}$, and through the $\pi-\pi$ interaction with the aromatic ring in GO Stacked. Coupled with the formation of hydrogen bonds with the hydroxyl groups of chitosan and GO, the synergistic effect of the two enables adsorption of anionic dyes [113]. Tannery wastewater is high salinity wastewater, which may affect the efficiency of wastewater treatment process. The effect of ionic strength on dye adsorption is very complex. Salts in wastewater may weaken the electrostatic interaction between the oxide

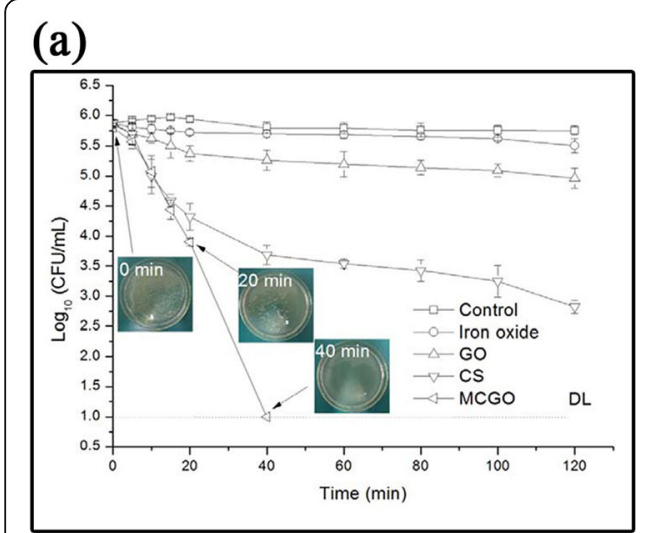

(c)

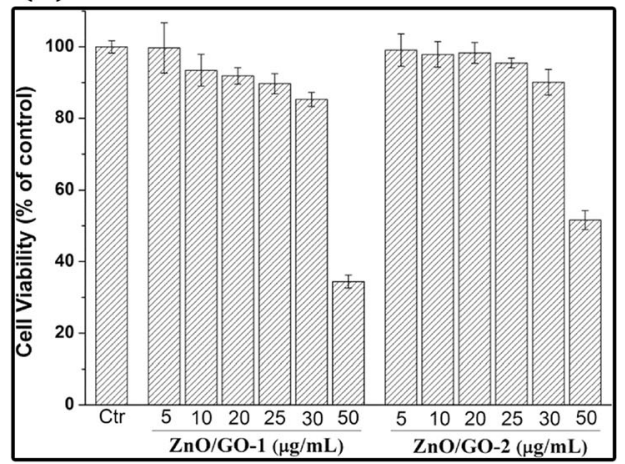

(b)

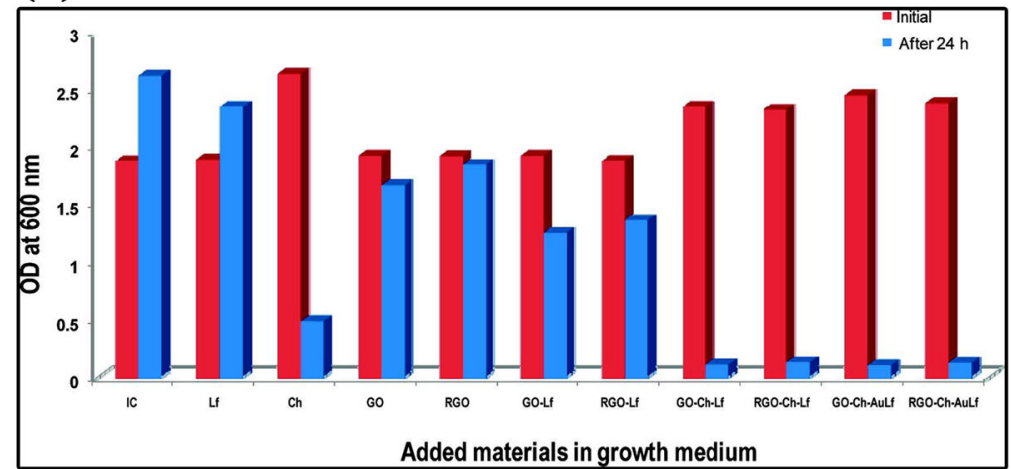

(d)

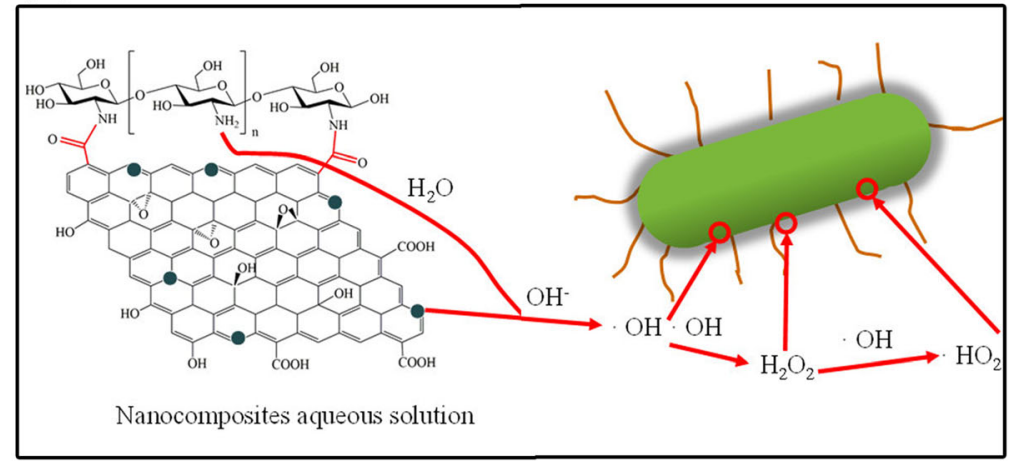

Fig. 9 a Antibacterial activity of iron oxide, GO, CS and MCGO against E. coli bacteria [106] Copyright 2016 International Journal of Biological Macromolecules. b A comparison of antibacterial activity of different materials tested [107] Copyright 2011 ACS Applied Materials and Interfaces; c Viability of HeLa cells after exposure to the ZnO/GO composites for 24 h [108] Copyright 2014 ACS Applied Materials and Interfaces; d Schematic presentation of antibacterial [35] Copyright 2016 Food Chemistry 
surface and dye molecules, resulting in a lower dye absorption rate during the adsorption process [114]. Liu et al. [115] showed that the adsorption of methyl blue on magnetic CS/GO had no significant relationship with ionic strength. $\mathrm{Na}^{+}$interacts strongly with the cation- $\pi$ of the GO aromatic ring, and the adsorption of chitosan-based composites was based on electrostatic effects, which overcomed the effects of salt ions [116]. Kashif et al. [117] showed that the adsorption of methyl violet and alizarin $\mathrm{R}$ by composites was reduced by only $5 \%$ and $7 \%$ in $20 \% \mathrm{NaCl}$. In summary, the effect of ionic strength on magnetic chitosan/GO is negligible.

On the contrary, it is similar to carbon nanostructurebased materials, we should consider their potential risks to the environment and their impact on the adsorption process $[118,119]$. A large number of environmental problems will be exposed. For example, as particles continue to grow, when they are released into the environment, it is likely to cause a large accumulation of sediment in the soil. The use of cheap biopolymers (such as chitosan) has considerable price advantages. The only expensive compound is GO [120]. In the long run, its price change curve will be similar to that of carbon nanotubes [121]. The preparation of CS/GO and its adsorption of some heavy metal ions and dyes are shown in Table 1.

\section{Conclusion}

As a unique biocomposite, chitosan-based composites have made great progress in its preparation and application. Among them, chitosan/collagen, chitosan/tannin acid, chitosan/polyethylene glycol, etc. Material preparation technology has matured, and its unique antibacterial properties and wetting properties have been widely used in medical, water treatment, electroplating, textile, food and other fields, bringing future dawn of green and functional production to the leather industry. Non-toxic, non-polluting and easily degradable chitosan and its derivatives, which have the characteristics of high bacteriostatic rate and strong adsorption, and have been used as leather bacteriostatic agents and dyeing auxiliaries. Although chitosan and its derivatives show excellent antibacterial properties in the leather industry, they still face many challenges.

(1) The degree of deacetylation of chitosan is related to the performance of chitosan, which requires in-depth research on the preparation and modification technology of chitosan to obtain chitosan with high degree of deacetylation, good water solubility, and high reactivity with

Table 1 The summarized of chitosan/GO composite applied in water treatment

\begin{tabular}{|c|c|c|c|c|}
\hline \multirow{2}{*}{$\frac{\text { Materials }}{\text { Chitosan/GO }}$} & \multirow{2}{*}{$\begin{array}{l}\text { Preparation } \\
\text { Ice-templated aerogel }\end{array}$} & \multicolumn{2}{|l|}{ Adsorption/mg·g-1 } & \multirow{2}{*}{$\frac{\text { Reference }}{[9]}$} \\
\hline & & Metanil yellow & 430.99 & \\
\hline Chitosan/GO/Fe3O4@SiO2 & Solution blending & $\mathrm{Cu}(\mathrm{II})$ & 429.06 & [13] \\
\hline Chitosan/GO/Fe3O4 & Sonication pulses & UI (IV) & 204.1 & {$[17]$} \\
\hline \multirow[t]{2}{*}{ Chitosan/collagen/GO } & Freeze drying & $\mathrm{Cu}(\mathrm{II})$ & 130 & [33] \\
\hline & & $\mathrm{Pb}(\mathrm{II})$ & 99 & \\
\hline \multirow[t]{2}{*}{ Chitosan/GO } & Freeze drying aerogel & Methyl orange & 686.89 & {$[41]$} \\
\hline & & Amido black 10B & 573.47 & \\
\hline Chitosan/GO/Fe3O4 & Co-precipitation & As (III) & 45 & {$[94]$} \\
\hline Modified Chitosan/GO/Fe3O4 & Solution blending & $\mathrm{Cu}(\mathrm{II})$ & 217.4 & {$[98]$} \\
\hline Chitosan/GO/Fe3O4 & Solvothermal & $\mathrm{Cr}(\mathrm{Vl})$ & 142.32 & {$[97]$} \\
\hline Chitosan/GO/Fe3O4 & Freeze drying & $\mathrm{Cr}(\mathrm{VI})$ & 153.85 & {$[95]$} \\
\hline \multirow[t]{2}{*}{ Chitosan/GO/Fe3O4 } & Freeze drying & $\mathrm{Ni}(I I)$ & 80.48 & [99] \\
\hline & & Reactive blue 19 & 102.06 & \\
\hline Chitosan/GO/Fe3O4 & Solvothermal & $\mathrm{Pb}(\mathrm{II})$ & 112.35 & {$[100]$} \\
\hline Chitosan/GO/Fe3O4 & Co-precipitation & Methyl orange & 398.08 & [106] \\
\hline \multirow[t]{2}{*}{ Chitosan/GO } & Casting & Methyl blue & 103 & [109] \\
\hline & & Methyl orange & 232 & \\
\hline Chitosan/GO/Fe3O4 & Sonication pulses & Disperse blue 367 & 298.27 & [113] \\
\hline Hierarchical mesoporous graphene/chitosan/Fe3O4 & One-step facile solvothermal & Methylene blue & 432 & [114] \\
\hline Chitosan/GO/CoFe2O4 & Freeze drying & Methylene blue & 382 & [119] \\
\hline Chitosan/GO/Fe3O4 & Co-precipitation & Methyl blue & 200 & [116] \\
\hline \multirow[t]{2}{*}{ Chitosan/GO/Fe3O4/ glutaraldehyde } & Solution blending & Methyl violet & 449 & [117] \\
\hline & & Alizarin yellow R & 348 & \\
\hline
\end{tabular}


collagen sugar. At present, the research of most scholars is how to further improve the antibacterial performance of chitosan, but while the antibacterial performance is improved, the binding capacity of chitosan and collagen may not necessarily be improved at the same time. When chitosan with high antibacterial properties enters the water body, the loss of activated sludge is extremely large, which makes it difficult to treat the tannery wastewater. Therefore, in the next study, the antibacterial properties of chitosan and the reactivity of chitosan with collagen should be balanced. The directional dispersion system and interface function of chitosan in collagen, the influence of chitosan on the structure and properties of leather is not fully understood. The interaction of chitosan, collagen, tanning agents, retanning agents, fatliquors and other substances, the adsorption of small molecules and metal ions on chitosan, $\mathrm{pH}$ and temperature, which will affect chitosan and collagen Interaction. The interaction determines the antimicrobial properties of the finished leather and the difficulty of treating the leather wastewater.

(2) Chitosan / graphene composite materials have broad application prospects in heavy metal removal, sterilization, dye removal, etc., but the treatment capacity of comprehensive wastewater is poor. Chitosan / graphene composite materials are easy to swell and peel in water, which requires further exploration of the separation and antibacterial mechanism of chitosan / graphene composite materials for the separator and antibacterial, so as to improve the structure and stability of chitosan / graphene composite materials. While achieving high-efficiency bacteriostasis of chitosan / graphene composite materials, it can also adsorb heavy metals and dyes to comprehensive wastewater.

(3) Chitosan / collagen, chitosan / tannin, chitosan / polyethylene glycol have been widely used in medicine, textile, food and other fields, but chitosan and its derivatives application is still fewer in the leather industry. Therefore, in the future, we should make good use of the advantages of high physical and mechanical properties of chitosan such as good film formation and strong bacteriostasis, expand its scope of application, increase the research on chitosan-based functional leather, promote the green and functional development of the leather industry, and enhance the competitiveness of leather products comprehensively.

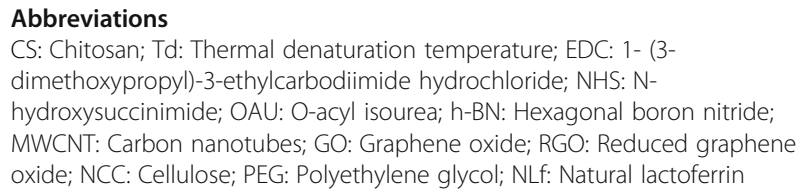

Acknowledgements

Not applicable.

\section{Authors' contributions}

YLL and YQD conceived the original idea and wrote the paper; LYX and DY analyzed the data; WYX performed the analysis. The author(s) read and approved the final manuscript.

\section{Funding}

This work was supported by Quanzhou City Science and Technology Program of China (Grant no. 2018G001, 2019G013).

\section{Availability of data and materials \\ Available.}

\section{Competing interests}

The authors declare that they have no competing interests.

\section{Author details}

${ }^{1}$ National Engineering Research Center of Clean Technology in Leather Industry, Sichuan University, Chengdu, Sichuan, P. R. China. ${ }^{2}$ Fujian Key Laboratory of Green Design and Manufacture of Leather, Jinjiang, Fujian, P. R. China. ${ }^{3}$ Xingye Leather Technology Co., Ltd. National Enterprise Technical Center, Jinjiang, Fujian, P. R. China. ${ }^{4}$ College of Manufacturing Science and Engineering, Sichuan University, Chengdu, Sichuan, P. R. China. ${ }^{5}$ School of Materials Science and Engineering, Shanghai Jiao Tong University, Shanghai, P. R. China.

Received: 6 March 2020 Accepted: 25 October 2020

Published online: 15 April 2021

\section{References}

1. Grégorio C. Historical review on chitin and chitosan biopolymers. Environ Chem Lett. 2019;17:1623-43.

2. Zou P, Yang X, Wang J, Li Y, Yu H, Zhang Y, Liu G. Advance in characterization and biological activities of chitosan and chitosan oligosaccharides. Food Chem. 2016;190:1174-81.

3. Chen Y, Dan N, Huang Y, Yang C, Dan W, Liang Y. Insights into the interactions between collagen and a naturally derived crosslinker, oxidized chitosan oligosaccharide. J Appl Polym Sci. 2020;137:48489.

4. Pangon A, Seasoo S, Seangkrit N, Ruktanonchai U, Intasanta V. Hydroxyapatite-hybridized chitosan/chitin whisker bionanocomposite fibers for bone tissue engineering applications. Carbohydr Polym. 2016;144:41927.

5. An X, Kang Y, Li G. The interaction between chitosan and tannic acid calculated based on the density functional theory. Chem Phys. 2019;520: 100-7.

6. Chauhan DS, Srivastava V, Joshi PG, Quraishi MA. PEG cross-linked chitosan: a biomacromolecule as corrosion inhibitor for sugar industry. Int J Ind Chem. 2018:9:363-77.

7. Muanprasat C, Chatsudthipong V. Chitosan oligosaccharide: biological activities and potential therapeutic applications. Pharmacol Ther. 2016;170: 80-97.

8. Fan X, Chen K, He X, Li N, Huang J, Tang K, Li Y, Wang F. Nano-TiO2/ collagen-chitosan porous scaffold for wound repairing. Int J Biol Macromol. 2016;91:15-22.

9. Lai KC, Hiew BY, Lee LY, Gan S, Thangalazhygopakumar S, Chiu WS, Khiew PS. Ice-templated graphene oxide/chitosan aerogel as an effective adsorbent for sequestration of metanil yellow dye. Bioresour Technol. 2019; 274:134-44

10. Wei W, Zhou YH, Chang HJ, Yeh J. Antibacterial and miscibility properties of chitosan/collagen blends. J Macromol Sci Phys. 2015;54:143-58.

11. Cui Z, Kim S, Baljon JJ, Wu BM, Aghaloo T, Lee M. Microporous methacrylated glycol chitosan-montmorillonite nanocomposite hydrogel for bone tissue engineering. Nat Commun. 2019;10:1-10.

12. Shao L, Chang X, Zhang Y, Huang Y, Yao Y, Guo Z. Graphene oxide crosslinked chitosan nanocomposite membrane. Appl Surf Sci. 2013;280:989-92.

13. Huang B, Liu Y, Li B, Liu S, Zeng G, Zeng Z, Wang X, Ning Q, Zheng B, Yang C. Effect of $\mathrm{Cu}$ (II) ions on the enhancement of tetracycline adsorption by Fe304@SiO2-chitosan/graphene oxide nanocomposite. Carbohydr Polym. 2017;157:576-85.

14. Roosen J, Roosendael SV, Borra CR, Gerven TV, Mullens S, Binnemans K. Recovery of scandium from leachates of Greek bauxite residue by 
adsorption on functionalized chitosan-silica hybrid materials. Green Chem 2016;18:2005-13.

15. Naseeruteen F, Adbul NS, Mohd FB, Wan WS, Mehamod FS. Adsorption of malachite green from aqueous solution by using novel chitosan ionic liquid beads. Int. J Biol Macromol. 2018;107:1270-7.

16. Habida U, Afifi AM, Salleh A, Ang BC. Chitosan/(polyvinyl alcohol)/zeolite electrospun composite nanofibrous membrane for adsorption of $\mathrm{Cr} 6+$, Fe3+ and Ni2+. J. Hazard Mater. 2017;322:182-94.

17. Huang G, Peng W, Yang S. Synthesis of magnetic chitosan/graphene oxide nanocomposites and its application for $\mathrm{U}(\mathrm{VI})$ adsorption from aqueous solution. J Radioanal Nucl Chem. 2018;317:337-44.

18. Badawi MA, Negm NA, Kana MT, Hefni HH, Moneem MM. Adsorption of aluminum and lead from wastewater by chitosan-tannic acid modified biopolymers: isotherms, kinetics, thermodynamics and process mechanism. Int J Biol Macromol. 2017:99:465-76

19. Xiang J, Ma L, Su H, Xiong J, Li K, Xia Q, Liu G. Layer-by-layer assembly of antibacterial composite coating for leather with cross-link enhanced durability against laundry and abrasion. Appl Surf Sci. 2018;458:978-87.

20. Yao Q, Liang Y, Wen H, Hong H, Yang Y, Dan W. Research progress of chitosan based composite materials and its application in leather industry. Leath Chem. 2019;36:16-29.

21. Taravel MN, Domard A. Relation between the physicochemical characteristics of collagen and its interactions with chitosan: I. Biomaterials. 1993;14:930-8.

22. Taravel MN, Domard A. Collagen and its interactions with chitosan: III. Some biological and mechanical properties. Biomaterials. 1996;17:451-5.

23. Domard A, Taravel MN. Collagen and its interactions with chitosan: II. Influence of the physicochemical characteristics of collagen. Biomaterials. 1995:16:865-71.

24. Socrates R, Prymak O, Loza K, Sakthivel N, Rajaram A, Epple M, Kalkura SN. Biomimetic fabrication of mineralized composite films of nanosilver loaded native fibrillar collagen and chitosan. Mater Sci Eng C. 2019;99:357-66.

25. Tozar A, Karahan $\mathbb{H}$. A comprehensive study on electrophoretic deposition of a novel type of collagen and hexagonal boron nitride reinforced hydroxyapatite/ chitosan biocomposite coating. Appl Surf Sci. 2018;452:32236.

26. Yang C, Dan N, You W, Huang Y, Chen Y, Yu G, Dan W, Wen H. Modification of collagen-chitosan membrane by oxidation sodium alginate and in vivo/ in vitro evaluation for wound dressing application. Int J Polym Anal Charact. 2019:24:619-29.

27. Oliveira PN, Montembault A, Sudre G, Alcouffe P, Maron L, Gehan H, Lux F, Albespy K, Centis V, Campos D, Roques S, Meulle M, Renard M, Durand M, Denost Q, Bordenave L, Vandamme M, Chereul E, Vandesteene M, Boucard N, David L. Self-crosslinked fibrous collagen/ chitosan blends: processing, properties evaluation and monitoring of degradation by bi-fluorescence imaging. Int J Biol Macromol. 2019;131:353-67.

28. Sionkowska MM, Kaczmarek B, Walczak M, Sionkowska A. Antimicrobial activity of new materials based on the blends of collagen/chitosan/ hyaluronic acid with gentamicin sulfate addition. Mater Sci Eng C. 2018;86: 103-8.

29. Puyana VP, Rosado MJ, Romero A, Guerrero A. Crosslinking of hybrid scaffolds produced from collagen and chitosan. Int J Biol Macromol. 2019; 139:262-9.

30. Sionkowaska A, Kaczmarek B. Preparation and characterization of composites based on the blends of collagen, chitosan and hyaluronic acid with nano-hydroxyapatite. Int J Biol Macromol. 2017;102:658-66.

31. Kaczmarek B, Sionkowska A, Kozlowska J, Osyczka AM. New composite materials prepared by calcium phosphate precipitation in chitosan/ collagen/hyaluronic acid sponge cross-linked by EDC/NHS. Int J Biol Macromol. 2018;107:247-53.

32. Türk S, Altinsoy I, Celebi G, Ipek M, Ozacar M, Bindal C. 3D porous collagen/ functionalized multiwalled carbon nanotube/chitosan/hydroxyapatite composite scaffolds for bone tissue engineering. Mater Sci Eng C. 2018;92: $757-68$

33. Zhang N, Qiu H, Si Y, Wang W, Gao J. Fabrication of highly porous biodegradable monoliths strengthened by graphene oxide and their adsorption of metal ions. Carbon. 2011;49:827-37.

34. Ibrahim MA, Priyadarhini BM, Neo J, Fawzy AS. Characterization of chitosan/ $\mathrm{TiO} 2$ nano-powder modified glass-ionomer cement for restorative dental applications. J Esthet Restor Dent. 2017:29:146-56.
35. Xu W, Xie W, Huang X, Chen X, Huang N, Wang X, Liu J. The graphene oxide and chitosan biopolymer loads $\mathrm{TiO} 2$ for antibacterial and preservative research. Food Chem. 2017;221:267-77.

36. Kumar PT, Lakshmanan VK, Anilkumar TV, Ramya C, Reshmi P. Unnikrishnan, Nair S V, and Jayakumar R. flexible and microporous chitosan hydrogel/ nano $\mathrm{ZnO}$ composite bandages for wound dressing: in vitro and in vivo evaluation. ACS Appl Mater Interfaces. 2012;4:2618-29.

37. Heidari F, Bahrololoom ME, Vashhaee D, Tayebi L. In situ preparation of iron oxide nanoparticles in natural hydroxyapatite/chitosan matrix for bone tissue engineering application. Ceram. Int. 2015;41:3094-100.

38. Xue J, Wang S, Han X, Wang Y, Hua X, Li J. Chitosan-functionalized graphene oxide for enhanced permeability and antifouling of ultrafiltration membranes. Chem Eng Technol. 2017:41:270-7.

39. Rozova EY, Zoolshoev ZF, Kuryndin IS, Saprykina NN, Elyashevich GK. Sorption and mechanical properties of chitosan/graphene oxide composite systems. Russ. J Appl Chem. 2019;92:415-22.

40. Majidi HJ, Babaei A, Bafrani ZA, Shahrampour D, Zabihi E, Jafari SM. Investigating the best strategy to diminish the toxicity and enhance the antibacterial activity of graphene oxide by chitosan addition. Carbohydr Polym. 2019;225:115220.

41. Wang Y, Xia G, Wu C, Sun J, Song R, Huang W. Porous chitosan doped with graphene oxide as highly effective adsorbent for methyl orange and amido black 10B. Carbohydr Polym. 2015;115:686-93.

42. Chen Y, Chen L, Bai H, Li L. Graphene oxide-chitosan composite hydrogels as broad-spectrum adsorbents for water purification. J Mater Chem A. 2013; 1:1992-2001.

43. Pan Y, Wu T, Bao H, Li L. Green fabrication of chitosan films reinforced with parallel aligned graphene oxide. Carbohydr Polym. 2011;83:1908-15.

44. Xie M, Zhang F, Peng H, Zhang Y, Li Y, Xu Y, Xie J. Layer-by-layer modification of magnetic graphene oxide by chitosan and sodium alginate with enhanced dispersibility for targeted drug delivery and photothermal therapy. Colloids Surf, B. 2019;176:462-70.

45. Zhang H, Luo X, Lin X, Lu X, Tang Y. The molecular understanding of interfacial interactions of functionalized graphene and chitosan. Appl Surf Sci. 2016;360:715-21.

46. Xie M, Lei H, Zhang Y, Xu Y, Shen S, Ge Y, Li H, Xie J. Non-covalent modification of graphene oxide nanocomposites with chitosan/dextran and its application in drug delivery. RSC Adv. 2016;6:9328-37.

47. Lei H, Xie M, Zhao Y, Zhang F, Xu Y, Xie J. Chitosan/sodium alginate modificated graphene oxide-based nanocomposite as a carrier for drug delivery. Ceram Int. 2016;42:17798-805.

48. Pan Y, Bao H, Lin L. Nancovalently functionlized multiwalled carbon nanotubes by chitosan-grafted reduced graphene oxide and their synergistic reinforcing effects in chitosan films. ACS Appl Mater Interfaces. 2011;3:4819-30.

49. Kosowska K, Pyzik PD, Nocuń M, Jan C. Chitosan and graphene oxide/ reduced graphene oxide hybrid nanocomposites - evaluation of physicochemical properties. Mater Chem Phys. 2018;216:28-36.

50. Hung W, Chang S, Lecaros RL, Ji Y, An Q, Hu C, Lee K, Lai J. Fabrication of hydrothermally reduced graphene oxide/chitosan composite membranes with a lamellar structure on methanol dehydration. Carbon. 2017:117:112-9.

51. Salehi H, Rastgar M, Shakeri A. Anti-fouling and high water permeable forward osmosis membrane fabricated via layer by layer assembly of chitosan/graphene oxide. Appl Surf Sci. 2017;413:99-108.

52. Kiechel MA, Schauer CL. Non-covalent crosslinkers for electrospun chitosan fibers. Carbohydr. Polym. 2013;95:123-33.

53. Sionkowska A, Kaczmarek B, Gnatowska M, Kowalonek J. The influence of UV-irradiation on chitosan modified by the tannic acid addition. J Photochem Photobiol B. 2015:148:333-9.

54. Qin L, Liu J, Li G, Kang Y. Removal of tannic acid by chitosan and Nhydroxypropyl trimethyl ammonium chloride chitosan: flocculation mechanism and performance. J Dispers Sci Technol. 2015;36:695-702.

55. Rivero S, García MA, Pinotti A. Crosslinking capacity of tannic acid in plasticized chitosan films. Carbohydr. Polym. 2010;82:270-6.

56. Rivero S, García MA, Pinotti A. Heat treatment to modify the structural and physical properties of chitosan-based films. J Agric Food Chem. 2012;60: 492-9.

57. Cowen S, Abadleh HA. DRIFTS studies on the photodegradation of tannic acid as a model for HULIS in atmospheric aerosols. Phys Chem Chem Phys. 2009:11:7838-47. 
58. Rubentheren V, Ward TA, Chee CY, Nair P, Salami E, Fearday CJ. Effects of heat treatment on chitosan nanocomposite film reinforced with nanocrystalline cellulose and tannic acid. Carbohydr. Polym. 2016;140:202-8.

59. Huang J, Cheng Y, Wu Y, Shi X, Du Y, Deng H. Chitosan/tannic acid bilayers layer-by-layer deposited cellulose nanofibrous mats for antibacterial application. Int J Biol Macromol. 2019;139:191-8.

60. Khan A, Khan RA, Salmieri S, Tien CL, Riedl B, Bouchard J, Chauve G, Tan V, Kamal MR, Lacroix M. Mechanical and barrier properties of nanocrystalline cellulose reinforced chitosan based nanocomposite films. Carbohydr. Polym. 2012;90:1601-8

61. Huang $X$, Xie F, Xiong X. Surface-modified microcrystalline cellulose for reinforcement of chitosan film. Carbohydr Polym. 2018;201:367-73.

62. Thakhiew W, Devahastin S, Soponronnarit S. Improvement of mechanical properties of chitosan-based films via physical treatment of film forming solution. J Food Eng. 2015;158:66-72.

63. Peršin Z, Maver U, Pivec T, Maver T, Vesel A, Mozetic M, Stanakleinschek K. Novel cellulose based materials for safe and efficient wound treatment. Carbohydr Polym. 2014;100:55-64.

64. Perelshtein I, Ruderman E, Francesko A, Fernandes MM, Tzanov T, Gedanken A. Tannic acid NPs-synthesis and immobilization onto a solid surface in a one-step process and their antibacterial and anti-inflammatory properties. Ultrason. Sonochem. 2014;21:1916-20.

65. Bozic M, Gorgieva S, Kokol V. Homogeneous and heterogeneous methods for laccase-mediated functionalization of chitosan by tannic acid and quercetin. Carbohydr Polym. 2012;89:854-64.

66. Kaczmarek B, Sionkowska A, Osyczka AM. Scaffolds based on chitosan and collagen with glycosaminoglycans cross-linked by tannic acid. Polym Test. 2018;65:163-8

67. Halim AL, Kamari A, Phillip E. Chitosan, gelatin and methylcellulose films incorporated with tannic acid for food packaging. Int J Biol Macromol. 2018; 120:1119-26.

68. Kaczmarek B, Sionkowska A, Osyczka AM. The comparison of physicchemical properties of chitosan/collagen/hyaluronic acid composites with nano-hydroxyapatite cross-linked by dialdehyde starch and tannic acid. Polym Test. 2017;62:171-6.

69. Boles LR, Bumgardner JD, Fujiwara T, Haggard WO, Guerra FD, Jennings JA. Characterization of trimethyl chitosan/polyethylene glycol derivatized chitosan blend as an injectable and degradable antimicrobial delivery system. Int J Biol Macromol. 2019;133:372-81.

70. Locharoenrat K. Preparation and metal removal from chitosan/PEG blend. Appl Mech Mater. 2016;835:348-52.

71. Lima DB, Almeida RD, Pasquali M, Borges SM, Fook MV, Lisboa HM. Physical characterization and modeling of chitosan/PEG blends for injectable scaffolds. Carbohydr Polym. 2018;189:238-49.

72. Mohamed RR, Seoudi RS, Sabaa MW. Synthesis and characterization of cross-linked polyethylene glycol/carboxymethyl chitosan hydrogels. Adv Polym Technol. 2015;34:1-6.

73. Jintapattanakit A, Mao S, Kissel T, Junyaprasert VB. Physicochemical properties and biocompatibility of N-trimethyl chitosan: effect of quaternization and demethylation. Eur J Pharm Biopharm. 2008;70:56371.

74. Dong R, Zhao X, Guo B, Ma PX. Self-healing conductive injectable hydrogels with antibacterial activity as cell delivery carrier for cardiac cell therapy. ACS Appl. Mater. Interfaces. 2016;8:17138-50.

75. Meemakshi M, Ciaran L, Catherine TD, Shyamali S, Satya P. A novel method for synthesizing PEGylated chitosan nanoparticles: strategy, preparation, and in vitro analysis. Int J Nanomedicine. 2011;6:485-94.

76. Bratskaya S, Privar Y, Nesterov DV, Modin EB, Kodess MI, Slobodyuk AB, Marinin D, Pestov AV. Chitosan gels and cryogels cross-linked with diglycidyl ethers of ethylene glycol and polyethylene glycol in acidic media. Biomacromolecules. 2019;20:1635-43.

77. Sundar VJ, Muralidharan C. Salinity free high tannin fixation vegetable tanning: commercial success through new approach. J Clean Prod. 2017; 142:2556-61.

78. Lv S, Yan X, Gao R. Preparation and properties of copolymer of methacrylic acid and acrylamide onto degraded chitosan initiated by HRP/H2O2/ACAC. Appl Mech Mater. 2011;80-81:396-9.

79. Aslan A. Improving the dyeing properties of vegetable tanned leathers using chitosan formate. Ekoloji. 2013;22:26-35.

80. Islam S, Butola BS, Roy A. Chitosan polysaccharide as renewable functional agent to develop antibacterial, antioxidant activity and colourful shades on wool dyed with tea extract polyphenols. Int J Biol Macromol. 2018;120: 1999-2006.

81. Dev VR, Venugopal JR, Sudha S, Deepika G, Ramakrishna S. Dyeing and antimicrobial characteristics of chitosan treated wool fabrics with henna dye. Carbohydr. Polym. 2009;75:646-50.

82. Fernandes IP, Amaral JS, Pinto V, Ferreira MJ, Barreiro MF. Development of chitosan-based antimicrobial leather coatings. Carbohydr Polym. 2013;98: 1229-35.

83. Luo Q, Gao H, Peng L, Liu G, Zhang Z. Synthesis of PEGylated chitosan copolymers as efficiently antimicrobial coatings for leather. J Appl Polym Sci. 2016;133:1-7.

84. Pollini M, Paladini F, Licciculli A, Maffezzoli A, Sannino A, Nicolais L. Antibacterial natural leather for application in the public transport system. J Coat Technol Res. 2013;10:239-45.

85. Lin Y, Li J, Chen W, Liu X, Jiang Q, Xia W. Geraniol grafted chitosan oligosaccharide as a potential antibacterial agent. Carbohydr Polym. 2017; 176:356-64.

86. Abdelkader A, Mokhtar MA, Adbelkader O, Hamad MA, Elsabahy M, Elgazayerly ON. Ultrahigh antibacterial efficacy of meropenem-loaded chitosan nanoparticles in a septic animal model. Carbohydr Polym. 2017; 174:1041-50.

87. Aranaz I, Harris R, Garcia FN, Heras A, Acosta N. Chitosan based films as supports for dual antimicrobial release. Carbohydr Polym. 2016;146:402-10,

88. Torres GS, Ocio MJ, Lagaron JM. Development of active antimicrobial fiber based chitosan polysaccharide nanostructures using electrospinning. Eng Life Sci. 2008:8:303-14.

89. Liu G, Li K, Luo Q, Wang H, and Zhang Z. PEGylated chitosan protected silver nanoparticles as water-borne coating for leather with antibacterial property. J. Colloid Interf. Sci. 2017; 490: 642-51.

90. Tseng H, Hsu S, Wu M, Hsueh TH, Tu PC. Nylon texiles grafted with chitosan by open air plasma and their antimicrobial effect. Fiber Polym. 2009;10:53-9.

91. Ista LK, Lopez GP. Interfacial tension analysis of oligo (ethylene glycol) terminated self-assembled monolayers and their resistance to bacterial attachment, vol. 28; 2012. p. 12844-50.

92. Goli KK, Pompa PP. Nanosilver-based antibacterial drugs and devices: mechanisms, methodological drawbacks, and guidelines. Chem Soc Rev. 2014;43:1501-18.

93. Lofrano G, Meric S, Zengin GE, Orhon D. Chemical and biological treatment technologies for leather tannery chemicals and wastewaters: a review. Sci Total Environ. 2013:461:265-81.

94. Bello M, Sherlala Al, Raman AA, Buthiyappan A. Adsorption of arsenic using chitosan magnetic graphene oxide nanocomposite. J Environ Manag. 2019; 246:547-56.

95. Zheng C, Zheng H, Wang Y, Wang Y, Qu W, An Q, Liu Y. Synthesis of novel modified magnetic chitosan particles and their adsorption performance toward Cr (VI). Bioresour Technol. 2018;267:1-8.

96. Yan M, Huang W, Li Z. Chitosan cross-linked graphene oxide/lignosulfonate composite aerogel for enhanced adsorption of methylene blue in water. Int J Biol Macromol. 2019:136:927-35.

97. Subedi N, Lähde A, Danso EA, lqbal J, Bhatnagar A. A comparative study of magnetic chitosan (chi@Fe3O4) and graphene oxide modified magnetic chitosan (chi@Fe3O4GO) nanocomposites for efficient removal of $\mathrm{Cr}(\mathrm{VI})$ from water. Int J Biol Macromol. 2019:137:948-59.

98. Hosseinzadeh $\mathrm{H}$, Ramin S. Effective removal of copper from aqueous solutions by modified magnetic chitosan/graphene oxide nanocomposites. Int J Biol Macromol. 2018;113:859-68.

99. Le TT, Le VT, Dao MU, Nguyen QV, Vu TT, Nguyen MH, Tran DL, Le HS Preparation of magnetic graphene oxide/chitosan composite beads for effective removal of heavy metals and dyes from aqueous solutions. Chem Eng Commun. 2019;206:1337-52.

100. Samuel MS, Shah SS, Bhattacharya J, Subramaniam K, Singh ND. Adsorption of $\mathrm{Pb}$ (II) from aqueous solution using a magnetic chitosan/graphene oxide composite and its toxicity studies. Int J Biol Macromol. 2018;115:1142-50.

101. Sudarshan NR, Hoover DG, Knorr D. Antibacterial action of chitosan. Food Biotechnol. 1992;6:257-72.

102. Hadwiger L A, Kendra D F, Fristensky B W, and Wagoner W. Chitosan both activates genes in plants and inhibits RNA synthesis in fungi, in R. Muzzarelli, C. Jeuniaux, G. Gooday (Eds.), Chitin in Nature and Technology, 1986; 209-214.

103. Akhavan $\mathrm{O}$, Ghaderi E. Escherichia coli bacteria reduce graphene oxide to bactericidal gaphene in a self-limiting manner. Carbon. 2012;50:1853-60. 
104. Liu S, Zeng TH, Hofmann M, Burcombe E, Wei J, Jiang R. Antibacterial activity of gaphite, gpahite oxide, graphene oxide, and reduced graphene oxide: membrane and oxidative stress. ACS Nano. 2011;5:6971-80.

105. Akhavan O, Ghaderi E. Toxicity of graphene and graphene oxide nanowalls against bacteria. ACS Nano. 2010;4:5731-6.

106. Jiang Y, Gong J, Zeng G, Ou X, Chang Y, Deng C, Zhang J, Liu H, Huang S. Magnetic chitosan-graphene oxide composite for anti-microbial and dye removal applications. Int J Biol Macromol. 2016;82:702-10.

107. Sreeprasad TS, Maliyekkal MS, Deepti K, Chaudhari K, Xavier PL, Pradeep T. Transparent, luminescent, antibacterial and patternable film forming composites of graphene oxide/reduced graphene oxide. ACS Appl Mater Interfaces. 2011;3:2643-54.

108. Wang YW, Cao A, Jiang Y, Zhang X, Liu J, Liu Y, Wang H. Superior antibacterial activity of zinc oxide/graphene oxide composites originating from high zinc concentration localized around bacteria. ACS Appl Mater Interfaces. 2014;6:2791-8.

109. Cortinez D, Palma P, Castro R, Palza H. A multifunctional bi-phasic graphene oxide/chitosan paper for water treatment. Sep Purif Technol. 2020;235 116181.

110. Kong $\mathrm{M}$, Chen $\mathrm{XG}$, Xing K, Park HJ. Antimicrobial properties of chitosan and mode of action: a state of the art review. Int J Food Microbiol. 2010;144:5163.

111. Hegab HM, Mekawy AE, Zou L, Mulcahy D, Saint CP, Ginicmarkovic M. The controversial antibacterial activity of graphene-based materials. Carbon. 2016;105:362-76

112. Ma J, Zhang J, Xiong Z, Yong Y, Zhao XS. Preparation, characterization and antibacterial properties of silver-modified graphene oxide. J Mater Chem. 2011;21:3350-2.

113. Taher FA, Kamal FH, Badawy NA, Shrshr AE. Hierarchical magnetic/chitosan/ graphene oxide 3D nanostructure as highly effective adsorbent. Mater Res Bull. 2018;97:361-8.

114. Hoa NV, Khong $T$, Quyen $\Pi$, Trung TS. One-step facile synthesis of mesoporous graphene/Fe3O4/chitosan nanocomposite and its adsorption capacity for a textile dye. J Water Process Eng. 2016;9:170-8.

115. Liu S, Ge H, Cheng S, Zou Y, Zhang K, Chu C, Gu N. Synthesis of graphene oxide modified magnetic chitosan having skin-like morphology for methylene blue adsorption. J Nanosci Nanotechnol. 2019:19:7993-8003.

116. Lu F, Luo C, Li X, Lu F, Qiu H, Sun M. Fabrication of novel magnetic chitosan grafted with graphene oxide to enhance adsorption properties for methyl blue. J Hazard Mater. 2012;215:272-9.

117. Kashif G, Saima S, Muttaqia W, Faiza A, Norulaini NA, Mohd AK. Functionalization of magnetic chitosan with graphene oxide for removal of cationic and anionic dyes from aqueous solution. Carbohydr Polym. 2016; 152:520-31.

118. Song B, Xu P, Zeng G, Gong J, Wang X, Yan J, Wang S, Zhang P, Cao W, Ye $S$. Modeling the transport of sodium dodecyl benzene sulfonate in riverine sediment in the presence of multi-walled carbon nanotubes. Water Res. 2018;129:20-8

119. Song B, Chen M, Ye S, Xu P, Zeng G, Gong J, Li J, Zhang P, Cao W. Effects of multi-walled carbon nanotubes on metabolic function of the microbial community in riverine sediment contaminated with phenanthrene. Carbon. 2019:144:1-7.

120. Sun W, Li M, Zhang W, Wei J, Chen B, Wang C. Sediments inhibit adsorption of $17 \beta$-estradiol and 17 a-ethinylestradiol to carbon nanotubes and graphene oxide. Environ Sci Nano. 2017;4:1900-10.

121. Volder MF, Tawfick SH, Baughman RH, Hart AJ. Carbon nanotubes: present and future commercial applications. Science. 2013;339:535-9.

\section{Publisher's Note}

Springer Nature remains neutral with regard to jurisdictional claims in published maps and institutional affiliations.

\section{Submit your manuscript to a SpringerOpen ${ }^{\circ}$ journal and benefit from:}

- Convenient online submission

- Rigorous peer review

- Open access: articles freely available online

High visibility within the field

- Retaining the copyright to your article

Submit your next manuscript at $\boldsymbol{\nabla}$ springeropen.com 